ISSN: $1130-3743$

\title{
TEORÍA Y PRÁCTICA DE LA ANIMACIÓN TEATRAL COMO MODALIDAD DE EDUCACIÓN NO FORMAL
}

\author{
Theory and practice in the theatre animation \\ as a modality of no-formal education
}

\author{
Xavier ÚCAR MARTÍNEZ \\ Universitat Autōnoma de Barcelona. Facultad de Ciencias de l'Educació. Departa- \\ ment de Pedagogia Sistemática i Social. Edifici G6. 08193. Bellaterra (Barcelona).
}

Fecha de aceptación definitiva: marzo de 2000.

BIBLID [(1130-3743) 11, 1999, 217-255]

RESUMEN

La animación teatral es aquel conjunto de prácticas socioeducativas con personas, grupos o comunidades que, a través de metodologías dramáticas o teatrales, genera procesos de creación cultural y persigue el empoderamiento (empowerment) de los participantes. Definimos esta metodología de la intervención socioeducativa como un punto de encuentro interdisciplinar en el que confluyen lo antropológico, lo educativo y lo artístico. Con este trabajo pretendemos analizar algunos de los útiles conceptuales, técnicos y prácticos en los que se fundamenta la AT. Se pretende, asimismo, presentar una visión panorámica de las diferentes formas que aquélla adopta al incardinarse en el trabajo sociocultural con personas, grupos y comunidades. Para ello hemos estructurado el análisis en tres bloques. En el primero reflexionamos sobre el contexto de la AT. En el segundo se profundiza en la conceptualización y los componentes básicos de dichos procesos. Con el tercero se busca, por último, conocer la situación actual y las perspectivas de futuro de esta metodología sociocultural y educativa de la intervención. Dicha situación se obtiene a través de una investigación en la que se describen, analizan, clasifican y contrastan diferentes experiencias de AT halladas en la red. 
The Theater Animation (TA) is a set of socioeducational practices with people, groups or communities that, through a theatre methodology, generate processes of cultural creation to aim the empowerment of participants. We define this methodology of socioeducative intervention as interdisciplinary meeting points in which meet the anthropology, the educational and the artistic. With this paper, we aim to analyse some of the useful concepts, techniques and practise in which the TA is based. We will present a general view of the different ways that TA adopt when it meet with the sociocultural works with people, groups or communities. For achieve this goal, we have structured the paper in three blocks. In the first, we think about the context of TA. In the second, we will centre on the conceptualisation and the basic components of those processes. In the third, we try to know the current situation and the future perspectives of this sociocultural methodology and educative of intervention. That situation is obtained through a research in which we describe, analyse, classify and contrast different experiences of TA found in Internet.

«El entretenimiento y el aprendizaje no se oponen; el entretenimiento puede ser el modo más efectivo de aprender». (Marcuse, 1990:97).

"Estoy convencido de que el inicio de una nueva vida dramática se establecerá fuera del teatro. ¿Será en la plaza pública? ¿Será en la casa de la cultura1? ¿Será en la iglesia? No lo sén. (Copeau, 1974:244).

"Todos nosotros somos teatro" (Boal) $)^{2}$.

$\mathrm{Ha}^{3}$ pasado poco más de un siglo desde que comenzamos a trabajar sobre la cultura como concepto ${ }^{4}$. A lo largo de este tiempo las reflexiones y análisis realizados sobre ella han ido aumentando exponencialmente hasta un final de milenio en el que resulta difícil hablar de cualquier tema sin referirse a su filiación cultural. La cultura, como concepto antropológico, se ha convertido en una matriz que posibilita la comprensión de cualquier realización humana. De hecho, parece que todo puede ser descrito, explicado e incluso comprendido si lo referimos a la cultura que lo produce.

En el macrocontexto perfilado por esta visión de la cultura, la animación sociocultural y el teatro pueden ser concebidos como herramientas y como productos

1. Maison du peuple en el original. El texto fue escrito en 1922.

2. Cit. Paterson, 1997.

3. Este trabajo corresponde a la ponencia leída por el autor en el Encontro Internacional sobre Animación Teatral organizado por el Consello da Cultura Galega en Santiago de Compostela en octubre de 1999.

4. La primera definición conocida sobre el concepto de cultura fue elaborada por el antropólogo cultural E. B. Tylor en el último cuarto del siglo XIX. 
culturales. En otros términos, ambos manifiestan una doble funcionalidad: posibilitan la integración o la vivencia de la cultura y constituyen, por sí mismos, una determinada expresión cultural. Una mirada hacia el pasado muestra, sin embargo, que las cosas no siempre han estado -al menos, conceptualmente- tan claras. Se podría llegar a decir que tanto el teatro como la animación -entendida ésta última en sentido amplio- han sido perseguidos por; han flirteado con; han sido usados por; han reivindicado frente; han sido tolerados por; han luchado contra; y, por último, han denunciado a; la cultura de los poderosos, la única tradicionalmente considerada como tal, la denominada cultura de elite.

A lo largo de la historia el teatro y la animación han estado junto a la cultura pero fuera de ella. Quizá ha sido esta misma exclusión la que les ha obligado a desarrollar la gran versatilidad que ambos despliegan en sus manifestaciones y prácticas. Teatro y animación se conjugan en esta herramienta cultural de trabajo con personas, grupos y comunidades que denominamos Animación Teatral5. Denominación ésta que, si bien resulta nueva en su formulación, es tan antigua como la propia humanidad si se piensa en su contenido y en sus procedimientos.

Con este trabajo pretendemos analizar algunos de los útiles conceptuales, técnicos y prácticos en los que se fundamenta la AT. Se pretende, asimismo, presentar una visión panorámica de las diferentes formas que aquélla adopta al incardinarse en el trabajo sociocultural con personas, grupos y comunidades. Para ello hemos estructurado el análisis en tres bloques. En el primero reflexionamos sobre el contexto de la AT. En el segundo se profundiza en la conceptualización y los componentes básicos de dichos procesos. Con el tercero se busca, por último, conocer la situación actual y las perspectivas de futuro de esta metodología sociocultural y educativa de la intervención. Dicha situación se obtiene a través de una investigación en la que se describen, analizan, clasifican y contrastan diferentes experiencias de AT halladas en la red.

\section{El CONTEXTO DE LA ANIMACIÓN TEATRAL: FAMIUIARES, AMIGOS Y VECINOS}

En una primera aproximación se podría afirmar que la cultura, la animación sociocultural y el teatro son los tres conceptos que parecen estar en la base de aquello que sea la AT. Serían, por así decirlo, los parientes más cercanos. Es a partir de estos familiares próximos que vamos a intentar establecer, en este apartado, una especie de genealogía que posibilite la comprensión de lo que es y lo que significa practicar ese punto de encuentro interdisciplinar que hemos convenido en denominar Animación Teatral.

Para el análisis partimos de los conceptos base y de su correspondiente filiación disciplinar: la cultura es el objeto de estudio de la antropología; la animación sociocultural lo es de la educación, en concreto, de la educación social; y el teatro

5. A partir de ahora AT en el texto. 
TEORÍA Y PRÁCTICA DE LA ANIMACIÓN TEATRAL COMO MODALIDAD DE EDUCACIÓN NO FORMAL

es estudiado por el arte. Los tres conceptos base hallan, en la disciplina que los estudia, su historia, su contexto de interpretación y sus metodologías y herramientas específicas, que determinarán la morfología con que cada uno de ellos se actualiza. Cada uno de ellos aporta, asimismo, unos rasgos específicos y diferenciados a la AT y contribuye a explicar, al menos, una parte de la misma.

De esta manera, como confluencia y diversidad de formas de trabajo y de expresión; como intersección de historias y tradiciones; y por último, como convergencia de modelos y corrientes, puede hacerse comprensible una metodología de trabajo antropológico, educativo y artístico tan plural, tan versátil y tan enriquecedora como la AT. En el cuadro № 1 pueden observarse de forma gráfica estos primeros planteamientos.

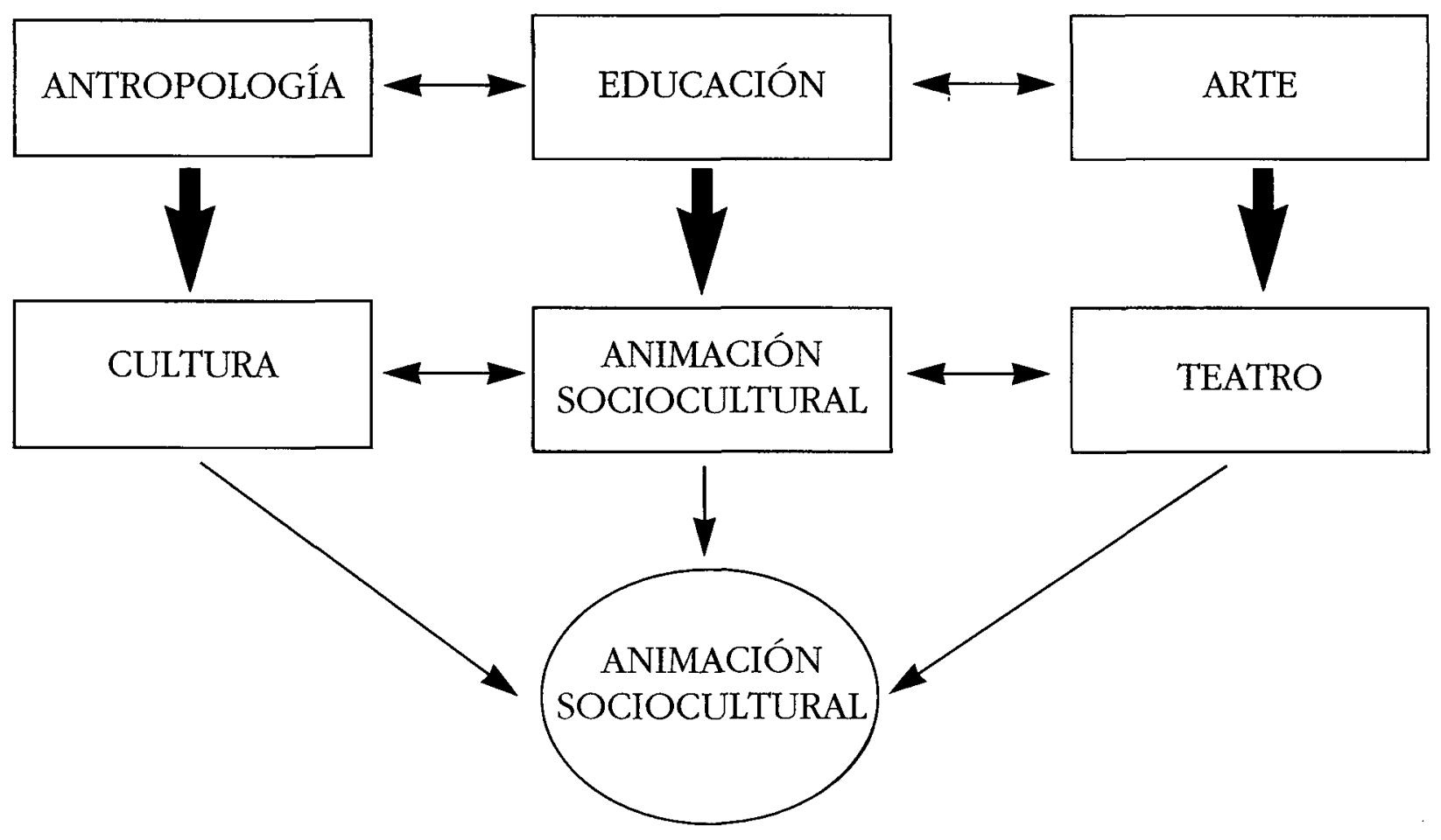

CUADRo № 1: Genealogía de la Animación Teatral.

Aquello que nos interesa saber, a continuación, es qué suponen, proponen o imponen estas filiaciones a la disciplina objeto de nuestro análisis. Es decir, en qué medida la AT es deudora de las finalidades, procesos y metodologías propios de cada una de estas disciplinas. Desde mi punto de vista, dicha filiación resulta determinante para poder establecer no sólo la conceptualización y las maneras de hacer propias de la AT, sino, también, por ejemplo, para definir y caracterizar el currículum formativo del animador teatral. A través del análisis y la confrontación de la AT con todos estos familiares, amigos y vecinos, irá emergiendo de forma gradual todo aquello que la define, limita y explica. 


\subsection{Cultura, modelos culturales y animación teatral}

En contra de lo que se podría pensar, el concepto de cultura y, sobre todo, la reflexión y la acción política sobre ella realizados, son fenómenos muy nuevos. De hecho, la reflexión colectiva sobre la cultura, como elemento de desarrollo de los pueblos, no comienza en Europa hasta después de la II a guerra mundial en el marco de unas instituciones supraestatales que se acababan de crear ${ }^{6}$. La primera conferencia, también mundial, sobre Políticas Culturales se desarrolló en Venecia en 1970; lo que significa que nos movemos en un ámbito de reflexión extraordinariamente joven. En las últimas décadas estos trabajos alrededor de la cultura han sido continuos y han generado diversas líneas de intervención en lo cultural que, con mayor o menor énfasis, han ido siendo impulsadas y desarrolladas por los gobiernos de los diferentes Estados.

La primera idea fue la de generalizar la cultura de elite acercándola a las capas de población que tradicionalmente no habían tenido acceso a ella. Fue la perspectiva denominada Democratización cultural. Perspectiva que, entre otras cosas, posibilitó el desarrollo de las industrias culturales y que se extendió, a partir de la década de los 70, a caballo de los medios de comunicación social. Se inauguraba la época del consumo cultural de la mano de los procesos de difusión cultural y de las inversiones de las empresas privadas en cultura 7 . Hasta este momento el concepto de cultura hace referencia tan solo a las artes y al patrimonio. La cultura era entendida únicamente como cultura artística. Es lo que en otro lugar hemos denominado concepto tradicional o pragmático (Etxeberría/Trilla/Úcar, 1994), por oposición al concepto antropológico de cultura que, en aquellos momentos, se disponía a entrar en escena.

En los años 80 se plantea una nueva perspectiva que supone un cambio cualitativo en las concepciones sobre la cultura. Se enuncia la perspectiva denominada Democracia cultural que entiende la cultura no como objeto de consumo sino como un ámbito de desarrollo personal y colectivo. Esta perspectiva se fundamentará en una definición antropológica de la cultura ${ }^{8}$ que se presenta en la Conferencia Mundial sobre Políticas Culturales realizada en Méjico en 1982. La cultura -se afirma en dicha conferencia- es el conjunto de rasgos distintivos, espirituales $y$ materiales, intelectuales y afectivos que caracterizan una sociedad o un grupo social. Engloba además, las artes y las letras, los modos de vida, los derechos fundamentales del ser bumano, los sistemas de valores, las tradiciones y las creencias. A partir de este momento el concepto de cultura permanecerá definitivamente

6. El Consejo de Europa y el Consejo de Cooperación Cultural entre otras. Ver Úcar, 1992.

7. Esta perspectiva se manifiesta como una visión oligárquica de la cultura: unos pocos la generan y el resto acceden sólo como espectadores o consumidores. Zallo ilustra muy bien el fracaso, en las sociedades desarrolladas, de los proyectos encarnados en este modelo cultural. Fracaso generado por la propia crisis que afecta al denominado Estado del Bienestar (1992).

8. Que venía a abundar en la ya citada de E. B. Tylor. 
ligado a la historia y a las diferentes formas y estilos de vida de los pueblos, a la manera como se relacionan con otros grupos humanos y a la forma en que interaccionan con su entorno. La nueva cultura definida es cultura vital, cultura de vida y no solo cultura artística. Ésta última se constituye como una dimensión más entre las muchas que configuran lo antropológico.

El nuevo modelo se actualiza a través de los denominados procesos de creación cultural, que se basan en la idea de que la cultura no es algo que únicamente las elites o los artistas pueden producir o crear. La creación cultural constituye un proceso colectivo de producción que, desde el bagaje cultural y tradicional de una comunidad y a través de la participación activa de sus miembros, procura generar nuevas actividades, procesos y productos, que sitúen a la citada comunidad en una línea de avance y de progreso y que contribuyan a una mejora sustantiva de la calidad de vida de sus miembros.

A finales de los 90 se sigue abundando y profundizando en el enfoque de la democracia cultural9. En el Informe Mundial sobre la Cultura -el denominado Informe Pérez de Cuellar - se redefine y amplía el papel de la cultura en la socie$\mathrm{dad}^{10}$. La cultura no es solamente un instrumento del progreso material, sino que es el fin y el objetivo del desarrollo, entendido éste último como realización de la existencia humana en todas sus formas y en toda su plenitud. No es que la cultura posibilite el desarrollo, sino que el mismo desarrollo es cultural, está culturalmente condicionado y, en consecuencia, puede asumir formas diferentes en función de la cultura en que se produce. En este nuevo modelo la cultura juega un papel constructivo, constitutivo y creativo en la vida de las sociedades y tiene entidad en sí misma como marco y contenido del desarrollo de los pueblos.

En este mismo informe se recoge y define un nuevo concepto que se constituye en objetivo irrenunciable de esta cultura del desarrollo: el empoderamiento (empowerment). Se refiere a un proceso de autodeterminación cultural por el que las personas, grupos y comunidades se dotan de recursos para poder participar en, y al mismo tiempo determinar, las esferas de poder. El empoderamiento -se afirma en el informe- incluye la capacidad de poder expresarse plenamente a través de la riqueza de la identidad cultural (...) que evoluciona en función de sus capacidades para realizar sus propios deseos y aspiraciones (1997:62). Democracia cultural y empoderamiento son o deberían ser, a la vez, objetivos y procesos de cualquier acción o intervención sociocultural desarrollada con personas, grupos o comunidades.

9. A pesar de que en la vida cotidiana de nuestras sociedades desarrolladas coexisten los diferentes enfoques o modelos culturales definidos, se puede afirmar que el modelo que fundamentalmente se impulsa desde las instituciones y organismos internacionales es éste último.

10. En otro lugar he definido las que desde mi punto de vista son aportaciones básicas del documento: (a) Ligar el concepto de cultura al de desarrollo; el de desarrollo al de educación; y, como consecuencia, ampliar el concepto de Política Cultural. (b) Plantear toda.una serie de nuevos conceptos como, libertad cultural y empoderamiento y reformular otros como el de creatividad. (c) Definir los principios básicos de una nueva ética global para todo el planeta (Úcar, 1999). 
¿Qué aportan estos planteamientos a la AT? En primer lugar, proveen un marco interpretativo para desarrollar el trabajo de animación teatral: el modelo de la democracia cultural. Como modelo antropológico supone la existencia de patrones ideológicos de referencia que delimitan las finalidades a perseguir. La AT trabaja por la democracia cultural de grupos y comunidades y eso supone, entre otras cosas, procesos grupales o comunitarios de creación cultural en los que la participación, la solidaridad o la libertad cultural ${ }^{11}$ son elementos claves.

En segundo lugar, ayudan a delimitar las metodologías y objetivos propios de la AT. No todo el trabajo teatral con grupos o comunidades tiene por qué ser considerado animación teatral. Desde el modelo actualizado de cultura presentado, consideramos que son animación teatral todas aquellas prácticas con personas, grupos y comunidades que, a través de metodologías dramáticas o teatrales, generan procesos de creación cultural y persiguen el empoderamiento de los participantes. No hay que olvidar que una herramienta fundamental del trabajo teatral es la interpretación de papeles y que ésta es una estrategia extraordinariamente útil para trabajar el cambio de actitudes ${ }^{12}$ y ampliar los universos de referencia personales. Se trabaja bien -afirman Eines/Mantovani en el marco de la didáctica teatral- cuando se amplían los límites (1997:49). En este sentido el empoderamiento se constituye, desde mi punto de vista, en uno de los objetivos básicos de los procesos de animación teatral.

En la segunda parte de este trabajo se muestran ejemplos de experiencias o iniciativas de AT que se incardinan en el modelo de la democracia cultural. Entre ellas, el denominado teatro del oprimido; el teatro del desarrollo; y las llamadas comunidades centradas en el teatro y el cambio social.

\subsection{Educación, animación sociocultural y animación teatral}

El decreto del año 1991, por el que se fundan los estudios universitarios de educación social, zanja definitivamente la cuestión sobre la ubicación académica ${ }^{13}$ de la animación sociocultural. Las acciones o intervenciones de animación sociocultural son -al menos administrativamente desde entonces- trabajo educativo o, de forma más precisa, trabajo socioeducativo. Lo que significa que, si pensamos en la AT como en un tipo específico de animación sociocultural, estamos ya caracterizándola como acción socioeducativa. De hecho, este planteamiento no viene sino a abundar en lo ya señalado en el punto anterior al definir el empoderamiento

11. El Informe sobre la cultura aporta el concepto de libertad cultural, que es caracterizada como una libertad colectiva y definida como el derecho de que goza un grupo para seguir o adoptar el modo de vida que desea (1997:18).

12. A través de las denominadas técnicas de rol-playing.

13. Por poner un ejemplo, hasta mediados o finales de los 80 , la bibliografía sobre animación sociocultural estaba repartida, en las bibliotecas universitarias, entre los espacios asignados a pedagogía, a psicología y a sociología. 
como uno de los objetivos clave de los procesos de AT. La educación social se presenta como una vía apropiada para acceder a procesos personales, grupales y comunitarios de empoderamiento; una educación social que se vehicula a través de prácticas de AT.

Decir que la animación sociocultural y la AT son acciones socioeducativas no viene a señalar nada más que el hecho de que ambas desarrollan procesos educativos en ámbitos sociales y comunitarios. Pero esto resulta insuficiente. Hay que remarcar que la animación se refiere -es cierto- a procesos educativos, pero que éstos se caracterizan por ser especialmente participativos, vivos, humanos, dinámicos y desenfadados. Nos hallamos en el ámbito de la educación no formal. Es en las acciones propias de la animación -y más aún en la AT-donde se hace patente la cita con la que se iniciaba este trabajo: en ellas, entretenimiento y aprendizaje no sólo no se oponen sino que se conjugan.

Definida la AT como una modalidad específica de animación sociocultural, se hace necesaria una caracterización de ésta última para ver en qué forma sus rasgos se especifican en la primera. En otro lugar hemos señalado que, en función de las dimensiones que la configuran y del tipo de acciones que desarrolla, la animación sociocultural puede asumir, en sus prácticas concretas, tres formas de hacer diferenciadas ${ }^{14}$. De cada una de ellas se derivan respectivamente unos objetivos, unas tareas y unas funciones determinadas que suponen -al animador- una formación específica también diferenciada. A continuación se presentan estas dimensiones concretándolas para la AT.

Una primera forma de caracterizar a la AT consiste en definirla como una tecnología social inmaterial o de planeamiento. Con esto se enfatiza la dimensión técnica que la configura. Este planteamiento implica como tareas propias de la AT el diseño, el desarrollo y la evaluación -primero- de planes, proyectos y programas y -segundo- de técnicas, procedimientos e instrumentos teatrales, que se aplican en comunidades, territorios o grupos determinados. La función derivada, en relación con dichas personas, grupos y comunidades, es la de generar respuestas técnicas, esto es, eficaces y eficientes, a las situaciones o problemáticas concretas que están viviendo o padeciendo y esto siempre a través del teatro, el drama y las técnicas teatrales.

Muchas experiencias de teatro popular ${ }^{15}$ y de teatro del desarrollo responden a esta manera de hacer. Sea desde la Administración, sea desde un grupo de teatro concreto o desde una comunidad se elabora o se solicita un proyecto de tipo educativo o cultural que se implemente a través del teatro. Los objetivos pueden ser de lo más diverso: recuperar o mantener la tradición, sensibilizar frente a problemáticas concretas, culturizar, etc. Quizá el caso más claro lo constituyen las denominadas comunidades centradas en el teatro (community-based theater), en

14. Ver Úcar 1998a.

15. Un ejemplo concreto de un proyecto de estas características puede verse en Muñoz, 1992. 
TEORÍA Y PRÁCTICA DE LA ANIMACIÓN TEATRAL COMO MODALIDAD DE EDUCACIÓN NO FORMAL

las que una comunidad colabora con un grupo de especialistas en teatro para recoger, sistematizar y finalmente elaborar una representación teatral referida a su historia, sus costumbres o su cultura (World Communities, 1999:1).

La segunda manera de caracterizar a la AT consiste en considerarla una práctica social. Esto supone que, en las acciones de AT, interrelacionan seres humanos que -por el hecho de ser personas- ponen en juego sus intereses, deseos, expectativas, sueños y problemáticas en las interacciones que sostienen. Supone también, que dichas personas se relacionan desde los diferentes roles (líderes, seguidores, etc.) y estatus (profesionales, voluntarios, etc.) que desempeñan en la dinámica social y en los contextos concretos de interacción. Con este segundo planteamiento destacamos la dimensión relacional de la AT que comporta trabajar en función de principios y valores consistentes con una ética de la relación interpersonal.

Los objetivos y tareas propios de esta caracterización se centran en catalizar y canalizar las energías personales, grupales y comunitarias hacia proyectos comunes de mejora a través de la creación, mantenimiento y consolidación de puntos de encuentro entre las personas. Lo que se pretende, en último extremo, es crear o consolidar el tejido sociocultural. En este caso, las funciones de la AT consisten en ayudar, mediar o apoyar el que los grupos y las comunidades sean capaces de emprender acciones que den respuesta a sus propias realidades (situaciones, problemáticas, etc.). Ejemplos claros de esta segunda dimensión de la AT son las numerosas Pasiones ${ }^{16}$, Belenes vivientes, Moros y cristianos $\mathrm{y}$, en general, las muy numerosas representaciones teatrales históricas o tradicionales que se realizan a todo lo largo de nuestra geografía, sobre todo de la rural.

Se puede considerar -en tercer y último lugar-a la AT como una práctica social crítica. Con este planteamiento lo que estamos enfatizando es el papel liberador y emancipador que pueden desempeñar los procesos de AT. Éste resultará, sobre todo útil o apropiado, en aquellas situaciones grupales o comunitarias de necesidad primaria perentoria ${ }^{17}$ o en aquéllas otras en que, aquellos grupos y comunidades, estén sometidos a situaciones de explotación, sean éstas del tipo que sean. Desde esta dimensión los objetivos y tareas de la AT consisten en despertar y/o ayudar a desvelar conciencias y estimular la acción emancipadora de los grupos y comunidades con los que trabaja. El mismo Brecht indicaba con su segundo postulado que: es necesario un teatro que aplique y produzca aquellos pensamientos y sentimientos que tienen una función en el cambio de la sociedad misma (Cid/Nieto, 1998). La dimensión política de la AT se hace evidente en este planteamiento.

Las acciones teatrales con contenido reivindicativo o político tienen una larga tradición histórica. El teatro popular está lleno de experiencias que ejemplifican esta tercera dimensión de la AT. El teatro del desarrollo o el teatro-forum son moda-

16. Ver $\mathrm{n}^{\circ} 32$ en la relación de páginas web en el anexo 1 .

17. Niveles 1 y 2 de la pirámide de necesidades de Maslow. 
lidades concretas de AT que pueden también centrarse en esta dimensión. El siguiente texto ilustra un ejemplo en que ambas modalidades se combinan en una experiencia de AT que se desarrolló en Senegal. Al poner en escena sus problemas familiares (conflictos locales, Sida, maltratos a las mujeres, etc.), \{el grupo BAMTAARE\} propone a los protagonistas implicarse en sus análisis y sugerir sus propias soluciones. Se invita a los espectadores a representar ellos mismos las escenas y convertirse enteramente en actores. Los problemas evocados dan lugar a un debate público. Esta verdadera "catarsis" o "purgación de las pasiones" por el efecto dramático, facilita la toma de conciencia y el sentido de la propia responsabilidad, estimulando el compromiso personal y colectivo. (Le Rue, 1997:1).

Hay que señalar que -al igual que sucede en la animación sociocultural- difícilmente podrá encontrarse una experiencia concreta de AT que se centre o desarrolle en exclusiva una de estas tres dimensiones. Por el contrario, lo habitual será que las tres dimensiones se interconecten de forma compleja y creativa para generar procesos de creación cultural teatral en los que convivan de forma más o menos equilibrada y armoniosa lo técnico, lo relacional y lo político. En el cuadro № 2 pueden observarse estas dimensiones de la AT junto con la conceptualización específica que cada una de ellas supone.

\begin{tabular}{|c|c|c|}
\hline \multicolumn{3}{|c|}{ DIMENSIONES CONSTITUTIVAS DE IA ANIMACIÓN TEATRAI } \\
\hline $\begin{array}{l}\text { Caracterización: } \\
\text { La AT es una... }\end{array}$ & Objetivos y tareas que persigue & Funciones que cumple \\
\hline $\begin{array}{l}\text { Tecnología } \\
\text { social de } \\
\text { planeamiento }\end{array}$ & $\begin{array}{l}\text { Diseñar, desarrollar y evaluar: } \\
\text { - Planes. programas y proyectos de AT } \\
\text { - Técnicas, procedimientos e } \\
\text { instrumentos teatrales y educativos. }\end{array}$ & $\begin{array}{l}\text { Dar y/o posibilitar respuestas } \\
\text { técnicas (teatrales y educativas) a } \\
\text { problemáticas socioculturales. }\end{array}$ \\
\hline Práctica Social & $\begin{array}{l}\text { Catalizar y canalizar las energías } \\
\text { personales, grupales y comunitarias } \\
\text { hacia proyectos comunes de mejora } \\
\text { - Crear y/o consolidar puntos de } \\
\text { encuentro } \\
\text { - Crear y/o consolidar el tejido } \\
\text { sociocultural }\end{array}$ & $\begin{array}{l}\text { Ayudar, mediar o apoyar } \\
\text { el trabajo de grupos y comunidades } \\
\text { en sus realidades socioculturales }\end{array}$ \\
\hline $\begin{array}{l}\text { Práctica social } \\
\text { crítica }\end{array}$ & $\begin{array}{l}\text { Posibilitar la emancipación de } \\
\text { aquellos grupos y comunidades } \\
\text { sometidos o en situación de } \\
\text { explotación. } \\
\text { - Despertar y/o ayudar a desvelar } \\
\text { conciencias } \\
\text {-Estimular la acción }\end{array}$ & $\begin{array}{l}\text { Ayudar, liderar o posibilitar la } \\
\text { emancipación de personas, grupos } \\
\text { y/o comunidades }\end{array}$ \\
\hline
\end{tabular}

\section{CUADRO №. 2: Dimensiones que configuran la animación teatral} como modalidad específica de animación sociocultural. 


\subsection{Arte, teatro, y animación teatral}

La mímesis y la representación de acciones son capacidades personales que nos vienen dadas. Ambas se presentan como factores teatrales esenciales. Desde los primeros años los niños repiten las acciones que observan en su entorno e imitan lo que hacen los adultos y sus compañeros. Esto les sirve para ensayar conductas y para poner a prueba sus capacidades. La imitación es, en esencia, una acción individual que no demanda necesariamente la presencia de los otros, para su realización; sencillamente, una persona imita un modelo. La representación, por el contrario, es una acción social: la persona imita también a un modelo o realiza una acción cualquiera, pero siempre delante de otras personas que observan lo que hace. Ésta constituye la condición básica para poder hablar de teatro o de un fenómeno teatral. La situación teatral, reducida a la minima expresión, -afirma Bentley- consiste en que A personifica a B mientras C lo mira (1982: 146). Para que se produzca una situación teatral se necesitan, como mínimo, dos personas: una que representa y otra que la mira.

La finalidad del teatro, globalmente considerado, es la escenificación del drama. Para realizar esta escenificación, el teatro demanda la presencia de los artistas: personas capacitadas para desarrollar un arte. Si nos referimos al arte teatral, aquellas son los actores y las actrices ${ }^{18}$, profesionales de la escena que poseen un bagaje conductual (psicofísico y emocional) adaptable a las exigencias concretas de las situaciones escenificadas. El teatro-afirma Ubersfeld-pertenece a la vez a las artes de la ejecución (música, danza, etc.) y a las artes de la representación mimética (pintura, cine, etc.). Las primeras tienen como base el cuerpo bumano en relación o no con un instrumento que le prolonga: son las artes del tiempo, las artes de la presencia viviente (....) Las otras son las artes de la representación de la ausencia: el cuadro o la pelicula son también presentes, son un estar abi, pero figuran una ficción, una ausencia y tienen un soporte beteromaterial (1997: 46). La formación de actores persigue generar artistas, profesionales del arte teatral, esto es, de la representación de acciones e interacciones humanas. Personas que dominan toda una serie de registros comunicativos y los tienen disponibles para adecuarlos a las exigencias específicas de una acción dramática que, normalmente, estará especificada en una trama argumental concreta.

A pesar de la importancia que se asigna al método de formación en los estudios teatrales, lo que realmente cuenta es el producto final. El actor se prepara y forma para representar productos acabados: un personaje concreto en una determinada representación teatral. En otros términos, más que el proceso concreto de formación seguido, importa la calidad final de la formación; el resultado, la capacidad del actor para encarnar de forma creíble a diferentes personajes.

18. No olvido al resto de artistas -director, escenógrafos, luminotécnicos, etc-. A ellos nos referimos más adelante. 
En los procesos de AT el producto final -el espectáculo- no es lo que más importa. En la formación para el teatro profesional se prepara al actor para generar productos dramáticos, aquí se intenta que la persona se conozca mejor a sí misma y se dote de recursos para mejorar su relación con los demás y con su medio sociocultural. Lo verdaderamente formativo $-\mathrm{y}$, por tanto, culturizador- es el proceso de experimentación y creación teatral. El producto final, en forma de representación teatral, el espectáculo, si es que se produce, constituye tan sólo un incentivo personal y grupal al proceso de formación seguido.

La AT no pretende ni la formación de artistas ni la de actores profesionales. En todo caso, ambos fenómenos se pueden producir como resultados indirectos de las acciones desarrolladas. No en vano el teatro es definido y caracterizado como un arte. Ahora bien, Ubersfeld completa esta caracterización al apuntar que el teatro es un mensaje complejo que constituye a la vez la expresión de una práctica artística y un acontecimiento sociocultural (1997:29). Es esta doble caracterización la que posibilita un -también- doble desarrollo o práctica:

a) El teatro como arte profesional

b) El teatro como fenómeno sociocultural; del que se nutren o en el que se fundamentan los procesos de AT.

En Botswana, África, y en el ámbito del teatro del desarrollo se recoge esta doble caracterización. Se distingue entre lo que denominan drama populary drama de escenario. El primero constituye una experiencia muy cercana a las formas tradicionales del teatro africano; se representa en el local de la comunidad y sus miembros se convierten en actores para la ocasión. El segundo, por el contrario, es muy formalizado y se podría caracterizar como teatro profesional (Media Port, 1999:1).

\subsubsection{Caracterización del teatro desde los proyectos de animación teatral}

Pensar el teatro desde los procesos de AT, equivale a describir una multiplicidad de acciones e intervenciones que se caracterizan, en primer lugar, por su extraordinaria heterogeneidad. El teatro, como estrategia de animación, toma en las iniciativas que se llevan a cabo en la práctica, una dimensión múltiple; talleres de teatro impartidos a colectivos específicos (jóvenes, mujeres, presos, etc.); montajes teatrales llevados a cabo por grupos de amigos o por comunidades concretas ${ }^{19}$; Teatro histórico o tradicional; y cursillos, jornadas o experiencias de teatro popu-

19. Como ya se ha señalado, en España es muy común que determinadas celebraciones religiosas (la pasión, el nacimiento o la vida de Cristo) sean representadas teatralmente por los miembros de las comunidades, a menudo, rurales. Son especialmente conocidas las "Pasiones" y los "Belenes vivientes». Todas ellas son experiencias de AT. Para una caracterización y evaluación de dichas experiencias ver Úcar, 1993. 
TEORÍA Y PRÁCTICA DE LA ANIMACIÓN TEATRAL COMO MODALIDAD DE EDUCACIÓN NO FORMAL

lar, por poner algunos ejemplos. Todo este heterogéneo conjunto de actividades constituye el instrumental básico de los procesos de AT.

En el marco de dichos procesos vamos a presentar una síntesis de los rasgos que, desde nuestro punto de vista, caracterizan esencialmente al teatro y se constituyen en presupuestos previos de cualquier programa o proyecto de AT:

- El teatro es un fenómeno humano en el que concurren, participan, o se ponen en juego, al mismo tiempo, las facetas individual y social de las personas.

- El objeto del teatro es la representación de situaciones humanas, de dramas. Este término proviene del término griego drao, que significa: acción, acción representada o gente en acción. Las personas, sus problemáticas, sus interacciones con los demás y con el entorno, constituyen su temática concreta.

- El teatro es, ante todo, un medio de expresión y de comunicación, a través del cual las personas pueden descubrir y experimentar sus límites y posibilidades, tanto en el ámbito personal como en el de las interacciones sociales. El cuerpo es el único instrumento de expresión utilizado por el ser humano desde el mismo instante de su nacimiento y es el propio cuerpo (entendido como una unidad psicofísica y emocional) el que se experimenta y se pone en juego en las acciones teatrales.

- El teatro desarrolla las funciones de divertir y educar. Se propone educar divirtiendo al mismo tiempo que forma un público apreciador del arte o fortalece el gusto de los que ya lo aprecian (O Hierofante, 1999:1).

- El teatro es un instrumento formativo al servicio del crecimiento, desarrollo y autonomía progresiva de las personas y las comunidades.

- El teatro es un punto de encuentro y descubrimiento para las personas, más allá de su edad, profesión o género. En él cada cual puede encontrar su sitio y su función. El teatro es inter y multigeneracional.

- El teatro, como instrumento de formación, es válido para el hombre en general porque es válido para todas las etapas de su desarrollo. En cada una de ellas tendrá unos objetivos predeterminados, habrá un estilo específico de hacer, y unas técnicas más adecuadas con relación al momento evolutivo $^{20}$.

- El teatro es siempre acción; constituye una experiencia eminentemente práctica. El contenido de esta experiencia práctica, de esta acción, centro del quehacer teatral, es el conflicto, como punto crítico a partir del cual se produce el descubrimiento, el crecimiento o el avance personal y/o comunitario en cualquiera de sus múltiples aspectos.

20. En Úcar 1992a: 25, 26 están descritas las características de una poética de teatro para niños, para adolescentes, para adultos y para gente mayor. 
- El teatro manifiesta un marcado carácter integrador. El poder de integración proviene del hecho que el lenguaje teatral es suma de muchos otros lenguajes (palabra, gesto, sonidos, colores, imágenes, formas, etc.).

- Las acciones dramáticas se basan en la capacidad para encarnar o desarrollar un papel o un personaje dentro de una situación ficticia. Esta situación se rige por el principio del juego simbólico, por el como si..., que es una técnica que permite la suposición de sujetos, hechos, y lugares simbólicos.

- Las acciones dramáticas posibilitan el uso simbólico del espacio y de los objetos. Desde el punto de vista formativo esto significa que favorecen y estimulan la capacidad de transferencia; la flexibilidad y la adaptación personal a situaciones nuevas; y el desarrollo de la imaginación y la creatividad de las personas.

- La acción dramática tiene en la catarsis uno de sus elementos más formativos $^{21}$.

- El teatro puede ayudar a las personas a desbloquear las inhibiciones naturales, traumas y represiones que rodean a las personas en la vida cotidiana, facilitándoles la adquisición de autoconfianza y confianza en los otros.

- El objetivo fundamental del teatro es proporcionar experiencias, instrumentos y recursos que permitan a las personas ampliar el número de registros expresivos y comunicativos a fin y efecto de ampliar y enriquecer su visión de la realidad y del mundo.

El objetivo del teatro, de cualquier tipo de teatro, es, o debe ser, enriquecer a las personas en uno u otro sentido, y la mejor forma de hacerlo es implementando su capacidad de relación con el mundo sociocultural que las rodea, haciendo que descubran, aprendan e integren el mayor número de registros expresivos y comunicativos posible. Es, en este sentido que afirmamos que, como modalidad específica de animación sociocultural, la AT busca que las personas se encuentren a sí mismas en la interacción con los otros; que descubran aspectos ignorados de las propias personalidades y que aprendan a rentabilizarlos en términos de mayor felicidad y equilibrio personal o interactivo; busca que aprendan a autoorganizarse para afrontar un problema colectivo. Busca en definitiva, crear un tejido sociocultural fuerte que fundamente la búsqueda organizada de una mejora sustantiva de la calidad de vida de un grupo o una comunidad. Y todo esto, a través de la utilización de procedimientos, técnicas y recursos teatrales.

\subsection{Teatro y animación sociocultural: el aprendizaje dramático}

El teatro es -como se ha señalado- una metodología de trabajo especialmente adecuada para desarrollar procesos de animación sociocultural. Desde el punto de

21. Para ampliar ver Úcar, 1992:20, 21. 
TEORÍA Y PRÁCTICA DE LA ANIMACIÓN TEATRAL COMO MODALIDAD DE EDUCACIÓN NO FORMAL

vista etimológico se afirma que el término animación proviene de anima (aliento vital, alma) y animus (dinamismo, movimiento). La propia historia, con múltiples ejemplos, nos muestra las veces que el teatro ha jugado o desarrollado ambos papeles, concienciando a las personas de las realidades que estaban viviendo e incitándolas a la acción ${ }^{22}$.

Tanto considerado como espectâculo al que se asiste o como creación autónoma de un grupo, el teatro puede situarse en la línea de los objetivos que persigue la animación sociocultural; básicamente, que las personas salgan de su pasividad, que se pongan en acción y que asuman o recobren su autonomía. El teatro, desde esta perspectiva, está íntimamente vinculado a la educación y se constituye esencialmente en un tipo de aprendizaje individual y colectivo, base y fundamento sobre el cual construir las nuevas interrelaciones de la comunidad con su propio medio sociocultural. Lo que denominamos aprendizaje dramático constituye el camino metodológico que el teatro proporciona para conseguir los objetivos que persigue la animación sociocultural.

Se podría afirmar que, en esencia, el objetivo procedimental básico de los procesos de AT radica en posibilitar que las personas, grupos y comunidades desarrollen, adquieran o experimenten aprendizajes dramáticos.

El aprendizaje dramático generado mediante la puesta en juego de procedimientos, técnicas y recursos teatrales y, al mismo tiempo, la gran potencialidad pedagógica que el teatro representa como herramienta fundamental en los procesos de AT, se hacen patentes en el hecho que aquél permite:

a) Una implicación de la persona como un todo armónico (cuerpo, mente, sentimientos y emociones) sin las eliminaciones y segmentaciones que se producen en muchas acciones de la vida cotidiana, donde, a menudo, se deben obviar, en los actos o en las decisiones a tomar, determinadas dimensiones como los afectos, los sentimientos o las emociones. De hecho, el teatro sensibiliza a las personas frente al mundo afectivo y no racional y les ayuda a integrarlo o a relacionarlo con el tipo de racionalidad -fundamentalmente técnica- en que se sustenta nuestra sociedad actual.

El teatro cuenta, por otra parte, como metodología de animación sociocultural, con la potencialidad de permitir a las personas trabajar con su inconsciente. En el teatro se enfrenta a la persona con las propias contradicciones, con sus miedos y sus complejos y se busca, con este enfrentamiento, que aquélla se proporcione a sí misma los instrumentos y los medios ade-

22. Dice Ubersfeld, el espectador está obligado no sólo a seguir una historia o una fábula, sino también a recomponer, en cada instante, la figura total de los signos que concurren en la representación. Al mismo tiempo, se debe apropiar (identificación) y alejar (distanciamiento) del espectáculo; la primera le permite vivirlo, la segunda pensarlo. Como indica esta autora, posiblemente no exista otra actividad que exija una tal toma de posición intelectual y psiquica. Es posible que aquí se encuentre la razón por la cual el teatro haya sobrevivido a las más diversas sociedades y bajo las formas más variadas (1989: 32). 
cuados bien para superarlos, bien para aprender a convivir con ellos. En este sentido, apunta González que el teatro moviliza continuamente a la persona, la sitúa delante de sus limites pero, para que los sepa esquivar o mezclar de tal manera que nunca la paralicen (1987:79).

b) La puesta en juego de los propios recursos expresivos y comunicativos de manera que conduzcan a las personas al autoconocimiento y al autodescubrimiento de los propios límites y posibilidades. El teatro es un campo de pruebas donde los individuos pueden experimentar y jugar con la creatividad propia y ajena. Procedimentalmente, los participantes intentan dentro de una situación lúdica o formativa, previa y/o tácitamente aceptada, pensar en sus interpretaciones y comprenderlas, analizando sus experiencias en la posterior puesta en común. En los procesos de animación teatral se aprende a través de la propia experiencia, no por un proceso puramente intelectual. Brecht ${ }^{23}$ decía que una característica de los medios teatrales es la transmisión de conocimientos e impulsos de una forma placentera; -y señalaba así mismo que- la profundidad del conocimiento $y$ del impulso corresponde a la profundidad del disfrute.

La puesta en práctica de conductas interactivas (de la misma forma que en el juego) sin peligro para la propia identidad física y psicológica. Esto comporta conocer y ampliar considerablemente el número de registros comunicativos e interactivos ${ }^{24}$ de las personas. Como apunta Ubersfeld, el teatro convoca y desactiva otro tipo de angustia, el de las relaciones bumanas, el de la relación con el Otro que puede destruirme y devorarme, con el otro que es más poderoso que yo, o más fuerte. El teatro es también el placer de una relación bumana mostrada sin sus peligros y puesta a distancia (1997:339).

23. Brecht: Écrits sur le teatre, 2, p. 545. Opus. Cit., 1997:329.

24. En teatro se dice que un actor es tanto más rico y creativo cuanto más registros posee. Un registro es un código determinado que permite acceder a un lenguaje específico (cualquier tipo de lenguaje: simbólico, analógico, etc.); dicho de otro modo, que permite establecer algun tipo de comunicación con los demás. Esto significa que cuantos más registros pueda utilizar una persona, más amplia y rica será su concepción del mundo y de la realidad. Significa también que estará mejor preparada para relacionarse y entenderse con los demás, y para vivir y enfrentarse a la realidad cotidiana. Esta especie de teoría de los registros se basa en la convicción de que la comunicación es mediadora en cualquier relación que la persona establezca, sea con ella misma (intracomunicación), con los otros (intercomunicación) o, incluso, con los objetos. Sólo si soy capaz de llegar a otra persona, de hacerme entender y de ser comprendido, en definitiva, de comunicarme en algún nivel con ella, puedo tener una razonable esperanza de iniciar una relación, de trabajar o vivir juntos, de autoorganizarnos, de soportarnos, de no llegar a la violencia, etc. Cualquier acción que dos personas quieran poner en práctica conjuntamente se fundamenta en la intercomunicación. En la medida en que puedo conectar con los registros del otro, puedo esperar de nuestra relación en el futuro. En este sentido, el teatro se nos presenta como un instrumento muy eficaz para investigar y ampliar los propios registros expresivos y comunicativos. Es también un campo de simulación que permite ponerlos en juego y observar la eficacia en la interacción con otros registros que utilizan otras personas. 
c) La observación de las reacciones de los demás (espectadores, grupo, comunidad, etc.) frente a las conductas propias, ajenas e interactivas, teniendo en cuenta que, a diferencia de otros tipos de observaciones de la vida cotidiana o del quehacer científico, en el caso del teatro, la persona se somete a la observación voluntariamente. El feed-back obtenido mediante estas observaciones enriquece el autoconocimiento y la capacidad relacional de las personas. El placer del teatro-dice Ubersfeld-es el de tocar con el dedo (pero tocar de lejos) todo lo que da miedo o ba dado miedo al niño (1997:339).

\section{LA ANIMACIÓN TEATRAL: CONCEPTO, METODOLOGÍAS, TÉCNICAS Y PROCEDIMIENTOS}

El camino recorrido a través del contexto y la genealogía de los procesos y prácticas de AT nos ubica frente a la tarea de conceptualizar aquello que pueda ser la AT. Un problema añadido es el de la terminología utilizada. El concepto de Animación Teatral define, caracteriza y distingue -claramente, desde mi punto de vista- un sector de prácticas socioculturales y educativas que se vehiculan a través del teatro y las técnicas teatrales. Muchas de las personas, grupos o comunidades, sin embargo, y, también muchas, de las experiencias e iniciativas, que en la actualidad forman parte de dicho sector, no se identifican a sí mismas con dicha denominación ${ }^{25}$. Éste es un fenómeno que suele suceder con las terminologías de nuevo cuño ${ }^{26}$.

\subsection{Animación teatral: la versatilidad de un concepto integrador}

Tratar con la AT supone, en este momento, un trabajo de integración conceptual que no resulta nada fácil si pensamos en la heterogeneidad, versatilidad y plasticidad de las tradiciones, metodologías, técnicas y procedimientos que convergen en ella. De los análisis contextuales previos podemos concluir que:

- La AT manifiesta una doble funcionalidad: puede ser concebida como un medio o una herramienta cultural (para acceder a la cultura) y como un fin, una expresión o un producto cultural (para expresar la cultura).

- La AT es un punto de encuentro interdisciplinar entre la cultura, la animación sociocultural y el teatro.

- La AT es una modalidad específica de animación sociocultural.

- El modelo antropológico que enmarca y orienta los procesos de la AT es el de la Democracia cultural.

25. Como se podrá comprobar en el siguiente punto, las terminologías utilizadas para caraterizar su actividad estan muy diversificadas.

26. En nuestro ámbito es Ventosa quien lo utiliza por primera vez en una publicación de 1990. El concepto es de origen francófono y proviene de prácticas teatrales comunitarias desarrolladas en Canadá. 
- La AT genera procesos de creación cultural en los que la participación, la solidaridad y la libertad cultural son principios clave.

- La AT trabaja en función de principios y valores consistentes con una ética de la relación humana.

- La AT puede ser caracterizada como una tecnología social de planeamiento, como una práctica social y como una práctica social crítica, siempre en función de los objetivos y metodologías en los que los procesos de animación pongan el énfasis.

- La AT pretende crear un tejido sociocultural fuerte que fundamente la búsqueda organizada de una mejora sustantiva de la calidad de vida de un grupo o una comunidad. Todo esto, a través de la utilización de procedimientos, técnicas y recursos teatrales.

- En los procesos de AT se aprende a través de la propia experiencia, no por un proceso puramente intelectual.

- En la AT se conjugan el entretenimiento y el aprendizaje. Los procesos de AT divierten al mismo tiempo que educan.

- La AT no busca como objetivo principal ni la formación de artistas ni la de actores profesionales.

- El objetivo procedimental básico de los procesos de AT consiste en posibilitar y estimular el aprendizaje dramático de personas, grupos y comunidades.

- La AT como sector de intervención sociocultural y educativa comporta una multiplicidad de acciones e intervenciones extraordinariamente heterogéneas y diversas.

A partir de estos presupuestos podríamos definir la Animación Teatral como aquel conjunto de prácticas socioeducativas con personas, grupos o comunidades que, a través de metodologías dramáticas o teatrales, genera procesos de creación cultural y persigue el empoderamiento de los participantes.

$\mathrm{Al}$ principio de este trabajo se apuntaba que no todo lo que se hace en teatro tiene porqué ser una experiencia de AT. ¿Qué es, entonces, lo que determina que una iniciativa concreta pueda ser o no incluida en este sector? En principio, parece claro que todas aquellas experiencias profesionales que tienen ánimo de lucro no formarían parte de lo que denominamos AT, pero es necesario matizar. En el cuadro № 3 se presentan algunos tipos de teatro y se concreta en qué condiciones pueden ser considerados como AT. 
TEORÍA Y PRÁCTICA DE LA ANIMACIÓN TEATRAL COMO MODALIDAD DE EDUCACIÓN NO FORMAL

\begin{tabular}{|ll|}
\hline No es... & \multicolumn{1}{c|}{ LA ANIMACIÓN TEATRAL } \\
Peatro profesional & $\begin{array}{l}\text { Pero puede serlo si... } \\
\text { o comunidad en el marco de los principios, valores o } \\
\text { metodologías de la democracia cultural (Cias. Profesio- } \\
\text { nales no lucrativas; Cias. profesionales que desarrollan } \\
\text { campañas de teatro popular; Cías. profesionales que } \\
\text { implementan campañas de teatro del desarrollo, etc.). }\end{array}$ \\
\hline Teatro escolar & $\begin{array}{l}\text {........forma parte de proyectos o campañas de cultu- } \\
\text { rización o de desarrollo del empoderamiento por } \\
\text { medio del teatro y las técnicas teatrales. }\end{array}$ \\
\hline Teatro experimental & $\begin{array}{l}\text {........no es un fin en sí mismo, sino un medio para } \\
\text { ampliar los recursos expresivos y comunicativos de los } \\
\text { participantes, por ejemplo. }\end{array}$ \\
\hline Teatro amateur & $\begin{array}{l}\text {........es algo más que pasar el rato y llenar el tiempo. } \\
\text { Si los objetivos que persigue se relacionan de alguna } \\
\text { manera con la mejora de la calidad de vida de la comu- } \\
\text { nidad. }\end{array}$ \\
\hline Etc... & \\
\hline
\end{tabular}

CUADRO №. 3: Rasgos que determinan que una experiencia teatral forme parte del sector de la AT.

En consonancia con la definición de AT elaborada y a partir de los análisis del cuadro anterior, dos parecen ser, en esencia, las características comunes a las diferentes experiencias o iniciativas teatrales. Estas características se muestran como los referentes para determinar qué experiencias pueden ser calificadas como AT. Serán consideradas experiencias o iniciativas de AT todas aquellas que:

A. En el marco de la Democracia Cultural persigan el empoderamiento de los participantes.

B. Generen o posibiliten procesos de creación cultural a través de procedimientos, técnicas o recursos teatrales.

2.2. Metodologías para la intervención: los teatros de la animación teatral.

La metodología de la intervención hace referencia a las relaciones establecidas entre los participantes -agentes y destinatarios de la acción-en los proyectos de AT y al contenido concreto de los intercambios o interacciones producidos entre ellos.

Dos son lo sujetos de cualquier proceso de AT: los animadores y el grupo específico con el que se desarrollan las tareas de animación. Este par de interlocu- 
tores asumen denominaciones tan variadas como diversos pueden ser los procesos de AT en los que se relacionan. Dichos procesos se producen entre, por ejemplo, de una parte: animadores profesionales, animadores voluntarios, grupos de teatro o empresas de servicios y, de otra, comunidades, clientes, empresas o colectivos específicos como reclusos, tercera edad o mujeres maltratadas. Las características de la relación, es decir, de la metodología de intervención ${ }^{27}$, vendrán condicionadas por el estatus que asuma cada uno de los interlocutores definidos. Es evidente que los procesos de AT desarrollados entre un grupo de teatro profesional que no persigue el lucro y una $O N G$ pueden diferir extraordinariamente de los producidos entre una empresa de servicios y un cliente, sea éste del tipo que sea.

En los proyectos de AT no existen estándares metodológicos para la intervención más allá de los principios clave definidos por el marco de la democracia cultural. Lo habitual será encontrar procesos metodológicos adaptados a las necesidades o demandas concretas de una situación, un grupo o una comunidad. La adaptación o la respuesta, sea a demandas o a necesidades detectadas, es un principio metodológico generalizable a cualquier proceso de animación sociocultural.

Otro de los factores que condiciona de forma definitiva la metodología de la intervención es el contenido o la denominación con la que se caracterizan las acciones realizadas o el propio proceso de AT. Es lo que hemos llamado los teatros de los procesos de AT. Algunos de estos teatros-que pueden operativizarse a través de muchas de las técnicas que se presentarán en el próximo apartado- son los siguientes:

a) El teatro-acción, teatro-forum o teatro-interactivo. Es considerado como un instrumento de la educación para el desarrollo. Consiste en representar una escena y, a continuación, interaccionar con la audiencia a través de preguntas y respuestas relativas a la acción.

b) El teatro popular es una estrategia de educación no formal, de creación artística colectiva y de promoción cultural para las comunidades. En el teatro popular se aplican dos principios (...): el autodidactismo y la participación social (Muñoz, 1992:4).

c) El teatro del oprimido. Desarrollado por el director de teatro brasileño A. Boal durante la década de 1950-60. Era un esfuerzo por transformar el teatro, del monólogo de los actores frente al público en las representaciones tradicionales, al diálogo entre la audiencia y el escenario. Es una forma de teatro-interactivo (Paterson, 1997).

d) El teatro de la concientización. También puede ser caracterizado como de teatro comprometido, de intervención o de resistencia. Consiste en utilizar el teatro para promover o estimular la toma de conciencia y el compromiso frente a todo tipo de problemas sociales.

27. Un ejemplo concreto de metodología de intervención en un proceso de AT puede verse en Teatro Camaleón, 1999. 
e) Teatro ritual, tradicional e indígena. Teatro étnico y multicultural. Estos tipos de teatro aparecen para intentar comprender la sabiduría que impregna los rituales y tradiciones de las culturas y naciones con el objeto de redefinir sus intenciones y significados en el contexto del mundo actual (ACP'sC, 1999:1).

f) El teatro-fiesta, que trata de ser una alternativa al teatro como representación. Este tipo de teatro enfatiza, la idea, próxima y motivadora, del teatro como juego (Cañas, 1992:57). En función de los objetivos perseguidos puede encarnarse en técnicas muy diversas como, por ejemplo, el bappening o las performances.

g) El teatro social que se define como la utilización del teatro para trabajar con personas caracterizadas como marginadas. Teatro social y humanitario que se centra en la educación y la prevención: teatro con deficientes psíquicos o mentales; teatro con jóvenes de barrios desfavorecidos; teatro con nómadas; teatro en condiciones especiales (guerra, hambre, etc.); y, por último, teatro como medicamento.

h) El teatro deportivo cuya metodología de trabajo emblemática es la técnica denominada match de improvisación. Consiste en un juego teatral colectivo que se desarrolla a través de reglas muy precisas. En él varios equipos compiten cooperativamente por medio de técnicas de improvisación mientras el público asistente es parte activa del espectáculo (Vio, 1996).

i) El teatro invisible que se caracteriza por adaptarse a las necesidades o demandas de una determinada situación al punto que la audiencia duda de si es o no una representación teatral.

j) El teatro del desarrollo o para el desarrollo. Es el que tiene por objeto la asistencia social, la reforma o el desarrollo de las comunidades. Es teatro para el debate, comprometido con el desarrollo y los problemas sociales. La primera experiencia se produjo en Botswana en 1974. Desde entonces se ha extendido por numerosos países de África (Media Port, 1999:1). También es caracterizado como teatro útil.

k) El teatro histórico. Consiste en la reconstrucción y posterior representación de todo tipo de sucesos culturales o históricos (reconstrucción de batallas en el mismo lugar donde se produjeron; evocación de historias comunitarias; rememoración de problemáticas o desastres acaecidos a un grupo humano, etc.).

En más de un caso hallaremos procesos de AT que se vehiculan a través de más de uno de los denominados teatros y, en consecuencia, pueden ser caracterizados de forma múltiple: una experiencia de AT puede vehicularse o ser, a la vez, teatro social, histórico y de concienciación, por ejemplo.

\subsection{Componentes básicos de los procesos de animación teatral: la nómina teatral}

Aunque no todos los procesos de AT consisten en el diseño, desarrollo y posterior representación de una obra de teatro, sí puede afirmarse que ésta parece ser una 
de las actividades y procesos más comunes. Esta es la razón para reflexionar sobre lo que puede considerarse como el núcleo de dicha actividad: la nómina teatral.

Se llama nómina teatral al conjunto de componentes que conforman el espectáculo. La conforman todos aquellos elementos que hacen posible la creación y la representación de un espectáculo teatral. En nuestro caso no lo referimos tanto al espectáculo final -dado que no tiene porqué ser el objeto del proyecto de animación- cuanto al propio desarrollo procesual de las experiencias de AT.

Se pueden contemplar los elementos siguientes como componentes de la nómina teatral ${ }^{28}$ :

a) El autor del texto teatral. Es quien elabora y proporciona el material primario a partir del cual se desarrolla el proceso de AT. A menudo será el propio grupo o la propia comunidad quienes construyan el texto y las acciones a representar a partir de las propias experiencias o de las historias vividas, recogidas o recordadas. Reconstruir la realidad que se vive o la historia que se recuerda ayuda a reformular las experiencias y la propia vida. Éste es un proceso altamente formativo ya que amplia y enriquece las perspectivas o los enfoques personales al posibilitar su contraste con las visiones de los demás.

Los procesos de AT desarrollados con los reclusos en las prisiones; las, ya citadas, comunidades centradas en el teatro; las experiencias de teatro del desarrollo; y el teatro del oprimido constituyen iniciativas de AT que mayoritariamente utilizan este procedimiento de trabajo. Apunta Ubersfeld que el paso del texto teatral-diálogo intercomunitario o intergrupal, en este caso- al texto representado no es una traducción ni una interpretación, sino una producción de sentido ${ }^{29}$ (1997:26). Este es el objetivo básico de muchas de las experiencias citadas al aplicar este procedimiento: la comprensión de la propia realidad. La catarsis, como función y efecto de la experiencia teatral, halla aquí su más clara expresión.

b) El texto teatral: la obra de teatro. Constituye el material primario, la base sobre la cual se articula todo el proceso de animación y se estructura la representación ${ }^{30}$, en el caso de que éste sea el objetivo final de la experiencia de AT. Aunque este material primario no haya sido elaborado por el grupo o la comunidad que implementa el proyecto de AT, es de destacar todo el proceso de análisis, estudio y consenso alrededor del texto para poder construir la dramaturgia ${ }^{31}$. El elemento formativo radica en la nece-

28. Me baso para estos elementos en Salvat, 1988. Él los refiere al teatro como actividad profesional, yo los adapto a las características concretas de los procesos de AT.

29. Remarcado en el original.

30. A través de las denominadas didascalias, apuntes entre paréntesis, en el texto teatral, que expresan y sugieren las acciones que acompañan cada uno de los parlamentos.

31. Está constituida por todos los elementos estructurales, temporales, psicológicos, situacionales, etc. que no forman parte del texto teatral y que es necesario reconstruir para poder representarlo. Con una analogía, si el texto escrito es el cuerpo, la dramaturgia es la pieza necesaria para manejarlo: la cabeza. 
TEORÍA Y PRÁCTICA DE LA ANIMACIÓN TEATRAL COMO MODALIDAD DE EDUCACIÓN NO FORMAL

sidad de compartir, negociar y dialogar las diferentes perspectivas sobre el contenido del texto. En las experiencias de teatro-acción, por ejemplo, este proceso de análisis se realiza entre los actores y el público al finalizar la representación teatral.

c) El director teatral. Es quien selecciona a los actores y guía y coordina sus respectivos trabajos con los de los denominados oficios teatrales: los especialistas -iluminador, escenógrafo, figurinista, etc.- y los técnicos -electricista, maquinista, sonido, etc.-, para conseguir montar el espectáculo. Es el responsable último del proyecto o de la representación teatral, si es el caso. Es quien tiene, a partir de un texto escrito, la visión global del espectáculo y la capacidad para convertir esta visión personal en algo vivo y tangible, en un producto representable. En los procesos de AT es el papel que habitualmente desarrolla el animador ${ }^{32}$. Herramientas básicas para el desarrollo de su trabajo son las técnicas teatrales.

Desde un punto de vista educativo se pueden definir las técnicas teatrales como aquel conjunto de actividades de simulación, de exploración y de investigación personal e interpersonal, sistematizadas y formalizadas, que, a través de la dramatización de acciones, posibilitan investigar, descubrir y/o poner en juego los registros expresivos y comunicativos de las personas. Dice González que la acción que se da con la práctica de estas técnicas es la sintesis creativa donde el individuo se descubre, y descubre también sus posibilidades como persona y como actor, si es que este último es su objetivo final. (1987:83). Responsabilidad del director-animador será crear un clima que posibilite dicha síntesis creativa.

Algunas de las técnicas que pueden utilizarse en los procesos de AT, más allá de si el objetivo final del proceso es o no una representación teatral, son:

$\Rightarrow$ Los juegos de desinhibición.

$\Rightarrow$ Los juegos rítmicos.

$\Rightarrow$ Las técnicas de relajación.

$\Rightarrow$ Las técnicas de estimulación sensorial y exploración física, personal e interpersonal.

$\Rightarrow$ Las técnicas de expresión corporal, mimo y pantomima.

$\Rightarrow$ Las técnicas de articulación, dicción y voz.

$\Rightarrow$ La improvisación.

32. A menudo este papel puede ser desarrollado por más de una persona si hay un gran número de participantes en el proceso. La Passió d'Esparraguera es una experiencia de AT en la que participan unas 400 personas como actores en un espectáculo que dura 12 horas. En él hay tres actores o actrices que interpretan cada uno de los papeles importantes. Eso les permite poder alternarse en la interpretación de la obra a lo largo de los dos meses en que se representa. De igual manera, la función directiva o animadora también está repartida: una persona se encarga de la dirección de actores (interpretación); otra de los movimientos de grandes grupos en el escenario; y, una tercera, de la organización y negociaciones entre los participantes para acordar los ensayos. 
$\Rightarrow$ La dramatización.

$\Rightarrow$ El psicodrama.

$\Rightarrow$ El sociodrama.

$\Rightarrow \mathrm{El}$ método Stanislavski/ Actor's Studio.

$\Rightarrow$ El método Grotowsky

$\Rightarrow$ Las máscaras y el maquillaje

$\Rightarrow$ Los títeres

$\Rightarrow$ Otras técnicas derivadas (rol-playing, sombras chinescas, etc.) ${ }^{33}$.

d) Los actores y actrices. Son quienes aportan los instrumentos vivos de la representación. El actor proporciona su cuerpo, su profesión y su experiencia, como una unidad armónica y funcional, para dar vida, con las indicaciones del director-animador, a unos personajes que sólo existen como letra impresa o diálogo compartido. Los actores y actrices, en los procesos de animación, son los propios participantes del grupo o la comunidad.

e) Los accesorios escénicos, cuya responsabilidad corre a cargo de los también denominados oficios teatrales. Son accesorios escénicos, todos aquellos recursos (decorado, luz, sonido, utillaje, vestuario, maquinaria, etc.) que hacen posible recrear ambientes o climas contemplados en el texto escrito o bien, pensados por el director-animador o por los propios participantes ${ }^{34}$.

En las experiencias de AT, los accesorios o recursos escénicos se presentan como un medio especialmente útil para generar procesos formativos. Cada uno de ellos puede ser objeto de un taller de trabajo específico. Por otra parte, a menudo nos encontramos en dichos procesos con personas que -sea por timidez, por bloqueos psicológicos personales o por otras problemáticas- tienen dificultades para interpretar o representar papeles. Disponer de actividades alternativas, también teatrales, permite que esas personas participen en el grupo y no se sientan excluidas. Permite, también, canalizar su participación en el proyecto e, incluso, iniciar el trabajo de ruptura de las problemáticas que los bloquean. No todos podemos o queremos interpretar y representar públicamente un personaje y ésa no ha de ser una razón para excluir a nadie de los procesos de AT. Esto es lo que nos ha llevado a atribuir al teatro, como actividad, un marcado carácter integrador: en él todos pueden encontrar su sitio y su función.

En lo que se refiere a los accesorios escénicos, se puede señalar que la mayor parte de ellos no constituyen -como señaló Grotowsky- algo esencial para la creación teatral. El teatro, como teatro pobre, actor-espacio-espectador, contiene en sí

33. En Úcar, 1992a, puede encontrarse una descripción, análisis, normas de aplicación, ejemplificación y valoración educativa de cada una de estas técnicas.

34. A menudo se ha definido al animador sociocultural como un gestor de la falta de recursos. En los procesos de AT dicha falta de recursos, de producirse, ha de ser subsanada por la creatividad y la imaginación del animador y los integrantes del grupo. Es necesario no olvidar que la acción teatral es, ante todo, artificio y que lo importante no es ser, sino parecer. Por ejemplificar, lo importante es que el vestido parezca de terciopelo, no que lo sea. 
mismo, los factores necesarios para producirse. No cabe duda sin embargo, que todos los elementos que lo acompañan enriquecen el proceso global. Al actor -en este caso grupal o comunitario- le ayudan a interpretar mejor su papel; al espectador a creer y vivenciar más intensamente las situaciones representadas; y al teatro, en general, a representar de una manera más fiel las realidades de sus tramas argumentales. Está claro que, a pesar de no ser esenciales, facilitan y potencian la fuerza expresiva del hecho teatral.

La manipulación de los objetos, el aprecio de las herramientas necesarias para cada trabajo y la habilidad en su utilización, son factores tan educativos y valiosos como la creación del texto teatral o la interpretación de personajes. En nuestra sociedad existe una tendencia a menospreciar los oficios teatrales por contraposición a las denominadas tareas creativas. Lo cierto es que en estos oficios teatrales reposa una herencia cultural de $\operatorname{siglos}^{35}$, que, en general, se ha transmitido en el círculo cerrado de los profesionales y que padece de un prurito gremialista que ha dificultado su conocimiento público ${ }^{36}$.

En la perspectiva sociocultural, los accesorios escénicos y los oficios teatrales manifiestan además otra potencialidad. La comunidad, en la que se desarrolla el proceso de AT, está conformada por profesionales de cariz diversificado. A menudo encontraremos personas con roles profesionales relacionados de una u otra manera con los citados oficios teatrales (carpinteros, sastres, electricistas, pintores, modistos, decoradores, contables, etc.). Cada uno de ellos puede ocuparse del accesorio escénico del que, en concreto, es especialista. Puede crear, de acuerdo con el animador y con los participantes, un pequeño grupo de trabajo o un taller con aquellas personas interesadas en aprender o participar en dicho accesorio escénico.

Cada taller se responsabiliza de la creación y elaboración de los productos necesarios para la representación de la obra de teatro. La información y la técnica de que dispone cada profesional estarán así al servicio de su propia comunidad. Un carpintero, por ejemplo, puede no solamente realizar técnicamente las tareas de maquinaria (construcción de decorados) necesarias para la representación teatral, sino también instruir a otras personas de la colectividad para una realización conjunta y un recíproco enriquecimiento. Ésta es la manera, por otra parte, de sectorializar los aprendizajes que conducirán después a una necesaria interrelación e intercomunicación entre los diferentes talleres o grupos de trabajo para el montaje de la obra.

Convencido de su potencialidad educativa, se enuncian a continuación, los accesorios escénicos y los oficios teatrales que hay que tener en cuenta en los procesos de animación teatral. Asimismo y, a modo de ejemplo, se presenta en el cuadro № 4 toda una serie de posibles profesiones implicadas en la puesta en marcha de una representación teatral y los, también posibles, talleres de formación y producción que podrían gestarse alrededor del montaje de la citada representación teatral en una comunidad concreta.

35. Que no cuenta -por cierto- en nuestro país con una tradición escrita.

36. Me refiero, por ejemplo, a técnicas tan concretas como el arregło de una cuerda rota. Técnicas inútiles frente a las nuevas tecnologías que se aplican en la actualidad en la maquinaria teatral. 


\begin{tabular}{|c|c|c|}
\hline $\begin{array}{l}\text { ACCESORIOS } \\
\text { ESCENICOS/ } \\
\text { OFICIOS TEATRALES }\end{array}$ & $\begin{array}{c}\text { POSIBLES } \\
\text { PROFESIONALES } \\
\text { IMPLICADOS }\end{array}$ & $\begin{array}{l}\text { POSIBLES } \\
\text { TALLERES }\end{array}$ \\
\hline $\begin{array}{l}\text { 1. La escenografía } \\
\text { y la maquinaria }\end{array}$ & $\begin{array}{l}\text { - Escenógrafo } \\
\text { - Pintor } \\
\text { - Dibujante } \\
\text { - Escultor } \\
\text { - Carpintero } \\
\text { - Maquinista } \\
\text { - Decorador } \\
\text { - Tramoyista } \\
\text { - Etc. }\end{array}$ & $\begin{array}{l}\text { - Taller de Escenografía } \\
\text { - Taller de Pintura } \\
\text { - Taller de Dibujo } \\
\text { - Taller de Escultura } \\
\text { - Taller de Carpintería } \\
\text { - Taller de Maquinaria } \\
\text { - Taller de decoración } \\
\text { - Taller de tramoya } \\
\text { - Etc. }\end{array}$ \\
\hline $\begin{array}{l}\text { 2. Los figurines } \\
\text { y el vestuario }\end{array}$ & $\begin{array}{l}\text { - Dibujante } \\
\text { - Patronista } \\
\text { - Figurinista } \\
\text { - Sastre } \\
\text { - Zapatero } \\
\text { - Modista } \\
\text { - Etc. }\end{array}$ & $\begin{array}{l}\text { - Taller de Dibujo } \\
\text { - Taller de Corte y confección } \\
\text { - Taller de Figurines } \\
\text { - Taller de Sastrería } \\
\text { - Taller de Zapatería } \\
\text { - Taller de Costura } \\
\text { - Etc. }\end{array}$ \\
\hline $\begin{array}{l}\text { 3. La iluminación } \\
\text { y la electricidad }\end{array}$ & $\begin{array}{l}\text { - Iluminador } \\
\text { - Electricista } \\
\text { - Ingeniero electrónico } \\
\text { - Etc. }\end{array}$ & $\begin{array}{l}\text { - Taller de Iluminación y color } \\
\text { - Taller de Electricidad } \\
\text { - Taller de Ingeniería electrónica } \\
\text { - Etc. }\end{array}$ \\
\hline $\begin{array}{l}\text { 4. El sonido } \\
\text { y la música }\end{array}$ & $\begin{array}{l}\text { - Técnico de sonido } \\
\text { - Ingeniero acústico } \\
\text { - Músicos } \\
\text { - Etc. }\end{array}$ & $\begin{array}{l}\text { - Taller de Sonido } \\
\text { - Taller de Ingeniería acústica } \\
\text { - Diversos talleres de música } \\
\text { (en función de instrumentos) } \\
\text { - Taller de ritmos musicales } \\
\text { - Etc. }\end{array}$ \\
\hline $\begin{array}{l}\text { 5. La regiduría } \\
\text { y el utillaje }\end{array}$ & $\begin{array}{l}\text { - Regidor } \\
\text { - Utillero } \\
\text { - Optimizador de tiempos } \\
\text { y procesos } \\
\text { - Etc. }\end{array}$ & $\begin{array}{l}\text { - Taller de Regiduría } \\
\text { - Taller de Utillaje } \\
\text { - Taller de Optimización de } \\
\text { tiempos y procesos } \\
\text { - Etc. }\end{array}$ \\
\hline 6. La producción & $\begin{array}{l}\text { - Productor } \\
\text { - Gerente y Administrativo } \\
\text { - Gestor } \\
\text { - Contable } \\
\text { - Etc. }\end{array}$ & $\begin{array}{l}\text { - Taller de Producción } \\
\text { - Taller de Gerencia y Administración } \\
\text { - Taller de Gestión y organización } \\
\text { - Taller de Contabilidad } \\
\text { - Etc. }\end{array}$ \\
\hline 7. La dirección ${ }^{37}$ & $\begin{array}{l}\text { - Director de proyectos } \\
\text { - Director de teatro } \\
\text { - Etc. }\end{array}$ & $\begin{array}{l}\text { - Taller de Dirección } \\
\text { - Etc. }\end{array}$ \\
\hline
\end{tabular}

CUADRO №. 4: Relación de profesionales implicados en cada uno de los accesorio escénicos y oficios teatrales, y subsiguientes talleres de AT.

37. Una descripción de todos estos oficios y accesorios puede encontrarse en Úcar, 1992a. 
Como se hace evidente en el cuadro, la riqueza que, un proceso de AT de estas características, puede aportar a una comunidad es muy grande.

f) Los técnicos teatrales. Son los que se ocupan de que, todos los aspectos técnicos de los accesorios o recursos escénicos, funcionen correctamente y en el momento adecuado. Como se ha apuntado éstos hallan su funcionalidad básica en la creación de grupos de trabajo o talleres específicos. En un proyecto de AT pueden ponerse en marcha tantos talleres o grupos de trabajo como accesorios teatrales o profesionales concretos haya, para desarrollarlos, en el grupo o comunidad.

g) El público. Constituido por todas aquellas personas que participan en el proyecto o asisten a la representación del espectáculo. En los procesos de AT a menudo estará constituido por miembros de la comunidad o de comunidades vecinas, por los propios participantes en el proceso o por sus familias y amigos.

En los proyectos de AT se pretende que el público sea algo más que simples espectadores que miran lo que otros hacen. Como señala Ubersfeld: el universo ficcional puesto frente al espectador convoca al universo referencial de éste, el universo de su experiencia vivida y su experiencia cultural (......) El espectador, a través del análisis de los signos de la representación, puede volverse el amo de los procesos sociales y de los procesos psíquicos, y el placer que saca de esto es el de toda actividad intelectual exitosa: el placer de comprender que no sólo es el placer de recibir sino también el de bacer (1997:335).

h) El lugar donde se desarrolla el proceso o se representa el espectáculo. El espacio donde se desarrolla el proyecto o la representación resulta determinante para el clima que se desea o espera lograr. A partir de las teorías de Artaud (1896-1948), y sobre todo desde la publicación de su ensayo El teatro y su doble (1938) se revoluciona la idea de espacio teatral. Artaud contempla la plaza central de los poblados primitivos como el espacio ideal para la realización de espectáculos. La clásica caja italiana, propia del teatro tradicional, deja de ser el espacio privilegiado para la representación de espectáculos teatrales. Más aún, con las nuevas tendencias teatrales, las performances, donde prácticamente cualquier tipo de espacio puede servir para la realización de un espectáculo. Montajes como los de La fura dels baus, Els Comediants o los de Peter Brook, muestran que un zoo, un cementerio, un edificio en obras, una cantera o la propia calle, pueden convertirse, por la acción de los intérpretes, en espacios idóneos para la representación teatral. En los procesos de AT lo habitual será que se reconviertan y reutilizen los espacios de la propia comunidad.

i) El escenógrafo o el responsable de la plástica teatral. El paso de la caja italiana al teatro circular comporta el paso de una visión bidimensional del espectáculo por parte de los espectadores, a una visión tridimensional (Sal- 
vat, 1988:14). Este cambio; la aparición de las nuevas tendencias estéticas, que transforman cualquier elemento de la cotidianeidad en arte; y, por último, la generalización de las nuevas tecnologías de la comunicación, amplían considerablemente la concepción plástica del espectáculo. Esto convierte al responsable de dicha concepción en un elemento determinante por lo que hace referencia al clima y, en consecuencia, al tipo de estimulación perceptiva y estética, que un espectáculo pueda producir en el espectador. En la AT será el taller de escenografía -siempre en colaboración con el director-animador- el responsable de la creación de dicho clima.

j) La producción. Desde el punto de vista del teatro como profesión, es el elemento clave de todo el proceso. Es el interlocutor de todos los profesionales que conforman el universo humano del teatro. Sus funciones son económicas y de gestión, y se centran básicamente en la elaboración del presupuesto necesario para poner en escena la obra de teatro, la consecución de dinero que permitirá montar el espectáculo, su distribución y administración por partidas mientras las representaciones estén en activo y la administración, en general, de todo el espectáculo. El productor se ocupa y es el responsable último de todo lo económico que hay en el espectáculo. Así, una buena producción puede asegurar la buena marcha del espectáculo, su éxito económico y, sobre todo, un buen clima entre los diferentes profesionales implicados en el montaje teatral. Todo lo dicho sirve para el proceso de animación teatral ${ }^{38}$.

\section{LOS PROCESOS DE ANIMACIÓN TEATRAL EN LA ACTUALIDAD}

Una buena manera de conocer la actualidad de los procesos de AT es rastrear la presencia de iniciativas o experiencias de esta naturaleza en la red. Aun siendo conscientes de que Internet está lejos de recoger la realidad de todas las comunidades del planeta, pensamos que puede ser un buen indicador o una referencia apropiada de lo que, en general, se está haciendo en el sector de la AT, al menos, en los denominados países desarrollados.

\subsection{La animación teatral en la red}

Para realizar la investigación en Internet era necesario precisar, previamente, el objeto concreto que había que buscar. Armado con el arsenal teórico definido

38. De hecho hay procesos de AT que pueden tener una producción extremadamente compleja. Para ejemplificar dicha complejidad económica y organizativa, basta pensar en el proceso organizativo y económico de la, ya citada, Passió d'Esparraguera. En este proyecto de AT estan implicadas unas mil personas de un pueblo que cuenta con unos 12.000 habitantes. 
TEORÍA Y PRÁCTICA DE LA ANIMACIÓN TEATRAL COMO MODALIDAD DE EDUCACIÓN NO FORMAL

en el segundo punto de este trabajo se especificaron los siguientes identificadores para la búsqueda 39 :

\begin{tabular}{|c|c|}
\hline IDENTIFICADORES: & PALABRAS CLAVE \\
\hline Animación tẻatral & Theatre \& education \& community \\
\hline Animation théâtral & Theatre \& community \\
\hline Animazione teatral & Social theatre \\
\hline Animaçao teatral & Theatre of the oppressed \\
\hline Teatro campesino & Theaterwork \\
\hline Teatro del oprimido & Community animation theatre \\
\hline Teatro popular & Théâtre \& communauté \\
\hline Theatre \& education & Theatre for development \\
\hline
\end{tabular}

CUADRO №. 5: Identificadores para la búsqueda de experiencias de AT.

A partir de estos identificadores se encontraron en la red 63 documentos -páginas web- que responden a los criterios especificados y que, como se observa en cuadro № 6 , se reparten de forma desigual entre diferentes países. Hay que señalar que se asigna, a la distribución de las experiencias por países, un valor más descriptivo que interpretativo, dado que es probable que las diferencias entre países estén fuertemente influenciadas por la presencia general que, respectivamente, cada uno de ellos mantiene en la red. Indicador claro de este hecho es la prácticamente nula presencia de iniciativas de este estilo en los países del denominado tercer mundo, cuando todo hace pensar que es un terreno abonado para experiencias de AT del tipo de teatro del oprimido, y, en general, teatro popular y del desarrollo.

\begin{tabular}{|l|c|c|}
\hline \multicolumn{1}{|c|}{ PAÍS } & No & $\%$ \\
\hline E.E.U.U. & 16 & 25.4 \\
\hline Francófonos (Canadá, 9) (Francia, 4) (Bélgica, 1) & 14 & 22.2 \\
\hline España & 14 & 22.2 \\
\hline Lusos (Portugal, 3) (Brasil, 2) & 6 & 9.5 \\
\hline África (Senegal, 1) (Mali, 1) & 6 & 9.5 \\
\hline Otros (Suiza, 1) (India, 1) (Italia, 1) (Chile, 1) (Venezuela, 1) (Filipinas, 1) (No consta, 1) & 7 & 11.2 \\
\hline \multicolumn{1}{|c|}{ TOTAL } & 63 & 100 \\
\hline
\end{tabular}

CUADRO №. 6: Países que constan en los documentos.

39. Quedaban excluidas, por tanto, todas aquellas experiencias que no cumplieran alguno de los dos requisitos definidos como imprescindibles para ser consideradas AT. Se hallaron experiencias que no cumplían algunos de estos requisitos en los ámbitos de: teatro profesional; teatro amateur; teatro escolar; Departamentos universitarios de teatro; Escuelas o Institutos artísticos; y teatro experimental. Éstos constituyen los límites de la investigación. 
TEORÍA Y PRÁCTICA DE LA ANIMACIÓN TEATRAL COMO MODALIDAD DE EDUCACIÓN NO FORMAL

Las variables que interesaba estudiar en los documentos hallados eran las siguientes:

a) Tipología de organizaciones que sustentan las prácticas de AT.

b) Objetivos explícitos del proceso o proyecto de AT.

c) Contenidos, actividades o metodologías utilizadas.

d) Grupo o grupos destinatarios de las acciones.

e) Caracterización (animación y/o formación) de las propias acciones.

A continuación se analiza cada una de estas variables.

\subsubsection{Tipología de organizaciones de animación teatral}

Como puede observarse en el cuadro № 7 las proporciones entre las categorías encontradas están muy repartidas, por lo que se hace difícil definir una organización en concreto como la más apropiada o la mejor para desarrollar procesos de AT. La heterogeneidad atribuida a las prácticas concretas de AT se reproduce también en las organizaciones que las soportan. Lo más genérico consistiría en afirmar que casi la mitad de las organizaciones que desarrollan estos procesos o proyectos son grupos de teatro o empresas de servicios.

\begin{tabular}{|c|c|c|}
\hline Tipología de organizaciones & No & $\%$ \\
\hline Grupo de teatro (Animación, 1) (Universitario, 1) (Popular, 1) (no profesional, 1) ${ }^{40}$ & 18 & 27.3 \\
\hline Empresa de servicios & 12 & 18.1 \\
\hline $\begin{array}{l}\text { Asociación no lucrativa (Municipal, 1) (civil, cultural, especializada en teatro, 6), } \\
\text { (educativa, 1) }\end{array}$ & 8 & 12.1 \\
\hline $\begin{array}{l}\text { Texto (Tesis doctoral, 1) (Asociación de teatro comunitario, 2) (Grupos de teatro, 3) } \\
\text { (Asociación no lucrativa, 1) }\end{array}$ & 7 & 10.6 \\
\hline Otros grupos e instituciones (Escuela de teatro, 1) (Grupo de animación, 1) (Museo, 1) & & \\
\hline (Centro de actividades y formación artística, 1) (Escuela, 1) (Ayuntamiento, 1) & 6 & 9.1 \\
\hline Universidad & 5 & 7.5 \\
\hline $\begin{array}{l}\text { Otras organizaciones (Rural, 1) (Regional, 1) (supranacional, 1) (ONG } \\
\text { no lucrativa estatal, 1) }\end{array}$ & 4 & 6.1 \\
\hline Documentos (Grupos de teatro, 1) (Boletín Informativo, 1) (universidad, 1) & 4 & 6.1 \\
\hline Contribución a un forum (Asociación, 1) (Grupo de teatro, 1) & 2 & 3.1 \\
\hline TOTAL & 66 & 100 \\
\hline
\end{tabular}

CuAdro №. 7: Tipología de organizaciones que desarrollan procesos de AT.

${ }^{40}$ Entre paréntesis las calificaciones con que algunas organizaciones se autodescriben. 
TEORÍA Y PRÁCTICA DE LA ANIMACIÓN TEATRAL COMO MODALIDAD DE EDUCACIÓN NO FORMAL

\subsubsection{Objetivos explícitos de los proyectos de animación teatral}

De las 63 páginas web recopiladas, 36 explicitan y definen 57 objetivos que se recogen y presentan en las categorías recopiladas en cuadro № 8 . Si se agrupan aún más dichas categorías, se observa que los objetivos giran alrededor de dos ejes que se formulan, caracterizan y concretan de formas variadas. Estos ejes son, en consonancia con la conceptualización realizada en apartados anteriores:

1‥ Educación/formación.

$2^{\circ}$. Creación cultural artística o creativa.

\begin{tabular}{|l|c|c|}
\hline \multicolumn{1}{|c|}{ Objetivos } & Total & $\%$ \\
\hline $\begin{array}{l}\text { Formación y educación para la toma de conciencia, el desarrollo, el respeto } \\
\text { al medio ambiente y el cambio social }\end{array}$ & 13 & 22.7 \\
\hline $\begin{array}{l}\text { Iniciar, promover, organizar u ofrecer servicios de carácter creativo, artístico, } \\
\text { cultural y turístico }\end{array}$ & 7 & 12.3 \\
\hline $\begin{array}{l}\text { Empoderamiento de personas y colectivos y mejora de la calidad de vida de } \\
\text { las comunidades a través del teatro }\end{array}$ & 7 & 12.3 \\
\hline $\begin{array}{l}\text { Apoyar, revitalizar, favorecer la comprensión, educar, y enriquecer la herencia, } \\
\text { la tradición y la cultura de las comunidades }\end{array}$ & 7 & 12.3 \\
\hline $\begin{array}{l}\text { Formación, capacitación y asesoría pedagógica y teatral de personas y grupos } \\
\text { teatrales y/o de formación }\end{array}$ & 6 & 10.5 \\
\hline Educar divirtiendo & 4 & 7.1 \\
\hline $\begin{array}{l}\text { Conocer el teatro y las prácticas y experiencias teatrales (Teatro de concientización, } \\
\text { de intervención, de resistencia, político, del oprimido, etc.) }\end{array}$ & 4 & 7.1 \\
\hline $\begin{array}{l}\text { Teatro de educación para la salud y al servicio de la prevención (toxicomanías, } \\
\text { alcoholismo, violencia, suicidio de adolescentes y maltratos) }\end{array}$ & 4 & 7.1 \\
\hline $\begin{array}{l}\text { Iniciar, promover y organizar manifestaciones culturales conjuntas entre artistas } \\
\text { y personas con hándicaps o discapacidades para contribuir a su integración } \\
\text { socioprofesional }\end{array}$ & 3 \\
\hline Fomentar la participación activa de públicos, audiencias y comunidades & 5.2 \\
\hline TOTAL & 2 & 3.4 \\
\hline
\end{tabular}

\section{CUADRO №. 8: Relación de objetivos explicitados por las organizaciones que desarrollan procesos de AT.}

\subsubsection{Contenidos, actividades o metodologías utilizadas}

En el cuadro № 9 se puede comprobar la variedad y heterogeneidad de contenidos, metodologías y técnicas para la intervención de que hacen gala los procesos de AT. También en estos aspectos se reproduce lo ya apuntado respecto a las organizaciones. Característica remarcable es que la formación, por una parte, y el teatro, por otra -ambos, genéricamente considerados- agrupan casi una tercera parte de los contenidos, actividades y metodologías definidos. Eso, teniendo en cuenta que, prácticamente, las dos terceras partes restantes constituyen especificaciones de aquellos dos. 


\begin{tabular}{|l|c|c|}
\hline Contenido/actividad/metodología & Total & $\%$ \\
\hline $\begin{array}{l}\text { Formación: cursos, seminarios, campañas de sensibilización, estudio de casos } \\
\text { (técnicas teatrales, pedagogía teatral, animación teatral, teatro de concienciación, } \\
\text { teatro de animación, expresión teatral con bandicapés, formación teatral } \\
\text { con discapacitados) }\end{array}$ & & \\
\hline Teatro & 16 & 10.7 \\
\hline Recursos humanos (asistencia técnica), de formación y teatro (técnicas teatrales) & 15 & 10.1 \\
\hline Teatro para el desarrollo: teatro útil & 13 & 8.5 \\
\hline Animación y dinamización teatral & 10 & 6.6 \\
\hline Pasacalles, Animación en barrios, Teatro en barrios y escuelas y Teatro de calle & 9 & 6.1 \\
\hline Animación cultural, animación creativa, arte y creación teatral (conjunta), & 7 & 4.5 \\
\hline Formación: Talleres (educativo, de expresión, teatral y circense, de teatro) & 7 & 4.5 \\
\hline $\begin{array}{l}\text { Técnicas teatrales (Psicodrama; Sociodrama; Teatro interactivo; Audiciones teatrales; } \\
\text { Cuadros humorísticos de pequeño formato; Role play; Dramatización de las propias } \\
\text { historias }\end{array}$ & 6 & 4.1 \\
\hline Improvisación & 5 & \\
\hline Animación & 5 & 3.4 \\
\hline $\begin{array}{l}\text { Proyectos (formación teatral; Desarrollo teatral y cultural en la marginalidad; } \\
\text { Teatro bistórico. Trabajo voluntario en los hospitales a través del teatro-clown }\end{array}$ & 5 & 3.4 \\
\hline Teatro popular y teatro del oprimido (técnicas) & 5 & 3.4 \\
\hline Animación y Teatro infantil & 5 & 3.4 \\
\hline Teatro social y humanitario: para la educación y la prevención & 4 & 2.7 \\
\hline Fiestas, canciones, danzas y animación de fiestas & 4 & 2.7 \\
\hline Teatro-forum y forum de discusión & 4 & 2.7 \\
\hline Juegos & 4 & 2.7 \\
\hline Variedades, (Malabares y Magia) & 3 & 2.1 \\
\hline Espectáculos & 3 & 2.1 \\
\hline Teatro-acción; & 3 & 2.1 \\
\hline Otras (Animación turística; Educación social; Publicidad teatral) & 3 & 2.1 \\
\hline Cuentacuentos & 3 & 2.1 \\
\hline Marionetas y títeres & 2 & 1.3 \\
\hline Animaciones itinerantes y Escuela de teatro itinerante & 2 & 1.3 \\
\hline Drama-terapia, teatro tearapeútico & 2 & 1.3 \\
\hline Teatro ritual, tradicional e indígena. Teatro étnico y multicultural & 2 & 1.3 \\
\hline \multicolumn{1}{|c|}{ TOTAL } & 2 & 1.3 \\
\hline
\end{tabular}

\section{CUADRO №. 9: Relación de contenidos, actividades} y/o metodologías utilizadas en los procesos de AT.

\subsubsection{Grupo o grupos destinatarios de las acciones de animación teatral}

En el cuadro № 10 se observan los colectivos destinatarios, de las acciones de AT, que se especifican en cada uno de los documentos hallados en la red. Parece evidente que algunas de las características que, en apartados anteriores, se atribuían al teatro, se hacen extensivas a los procesos de AT. Me refiero a su caracterización como inter y multigeneracional. Eso significaba que, en sus actividades, 
TEORÍA Y PRÁCTICA DE LA ANIMACIÓN TEATRAL COMO MODALIDAD DE EDUCACIÓN NO FORMAL

podían participar o bien grupos etarios específicos de cualquier etapa de la vida o bien grupos en que las edades se encuentran totalmente mezcladas. El primer caso son, por ejemplo, actividades de AT dirigidas o desarrolladas con jóvenes y, el segundo, actividades con comunidades en las que participan desde niños de pecho que acompañan a sus padres hasta abuelos y abuelas. Las, abundantemente citadas Passiones constituyen, también aquí, un buen ejemplo de esta segunda posibilidad.

\begin{tabular}{|l|c|c|}
\hline \multicolumn{1}{|c|}{ Grupo destinatario } & $\mathrm{N}^{\circ}$ & $\%$ \\
\hline Comunidades & 19 & 26,1 \\
\hline Todas las edades & 18 & 24.6 \\
\hline Público en general & 7 & 9.5 \\
\hline Personas, grupos y organizaciones. & 7 & 9.5 \\
\hline Jóvenes & 5 & 6.8 \\
\hline Niños y adolescentes & 4 & 5.4 \\
\hline Estudiantes & 3 & 4.2 \\
\hline $\begin{array}{l}\text { Profesores, Licenciados, diplomados profesionales de la enseñanza y } \\
\text { profesionales del teatro y la animación }\end{array}$ & 3 & 4.2 \\
\hline Instituciones y empresas & 2 & 2.7 \\
\hline Compañias profesionales, los grupos comunitarios y escolares y los artistas & 2 & 2.7 \\
\hline Personas enfermas y discapacitadas & 2 & 2.7 \\
\hline $\begin{array}{l}\text { Espectadores, comunidades terapéuticas; operadores sociosanitarios, } \\
\text { enfermos mentales, drogadictos }\end{array}$ & 1 & 1.4 \\
\hline \multicolumn{1}{|c|}{ TOTAL } & 73 & 100 \\
\hline
\end{tabular}

CUADRO №. 10: Relación de colectivos destinatarios de los procesos de AT.

\subsubsection{Caracterización de las acciones de animación teatral}

Otro dato que interesaba comprobar -dada la novedad del concepto que nos identifica- era la forma, con que cada una de las experiencias recopiladas, define o caracteriza los programas, proyectos y acciones concretas que desarrolla. Se trataba, en definitiva, de saber si dichas prácticas eran caracterizadas como Animación y/o como. Formación. Los resultados se recogen en el cuadro № 11. Quizás el dato más destacable, ya avanzado en el texto, es que hay casi una tercera parte de las iniciativas recogidas que no se caracterizan o definen como actividades de animación.

\begin{tabular}{|l|c|c|}
\hline \multicolumn{1}{|c|}{ Tipo de actividades referidas } & No & $\%$ \\
\hline Animación y formación & 18 & 28.5 \\
\hline Animación & 12 & 19.1 \\
\hline Formación & 32 & 51 \\
\hline Otras TOTAL & 1 & 1.4 \\
\hline \multicolumn{1}{|c|}{63} & 100 \\
\hline
\end{tabular}

CUADRO №. 11: Caracterización de las acciones en los procesos de AT. 


\section{BIBLIOGRAFÍA}

ACPC's THEATRE (The Asian Council for People's Culture). Theatre for the Environement Network. Publicación electrónica: http://fortunecity.com/victorian7museum/422/acpc2.html. Julio, 1999.

BENTLEY, E. (1982) La vida del drama. Ed. Paidós Studio. Barcelona

CAÑAS, J. (1992) Didáctica de la expresión dramática. Octaedro. Barcelona.

CID, L./NIETO, R. (1998) Técnica y representación teatrales. Acento. Madrid.

COPEAU, J. (1974) Registres I. Appels. Gallimard. París.

EINES, J./MANTOVANI, A. (1997) Didáctica de la dramatización. Gedisa. Barcelona.

ETXEBERRÍA, F.; TRILLA, J.; ÚCAR, X. (1994) “Educación no formal y políticas culturales", en, COLOM, A.J. (Edit.) Política y planificación educativa. Sevilla: Preu Spínola. Pp. 241-278.

GONZÁLEZ, L. (1987) El teatro. Necesidad bumana y proyección sociocultural. Popular. Madrid.

GROTOWSKI, J. (1970) Teatro laboratorio. Tusquets. Barcelona.

LAFERRIERE, G. (1997) La pedagogía puesta en escena. Naque. Ciudad Real.

LE RUE, S. (1997) Le théâtre au service de l'éducation au développement. Publicación electrónica. http://www.oneworld.org/euforic/eurodc/theatre.htm. Julio, 1999.

MARCUSE, H. (1990) El bombre unidimensional. Ariel. Barcelona.

MEDIA PORT. Guide du téâtre en Afrique et dans l'ocean indien: Botswana. Publicación electrónica: http://www.mediaport.net/AeC/Theatre/Pays/Botswana.en.html. Julio, 1999.

MUÑOZ, H. (1992) Teatro popular. Cuadernos de autoformación en participación social № 7. Ed. Instituto Nacional para la Educación de Adultos. México.

HIEROFANTE CIA TEATRAL Tudo Triim. Publicación electrónica: http://www.abordo.com.br/hierofante/triimm.html. Julio 1999.

PASQUAL, LL. (1999)“Educación y teatro", pp. 195-201, en Por una ciudad comprometida con la educación. Vol. 1. Ajuntament de Barcelona-Institut d'Educació. Barcelona.

PATERSON, D. (1997) Theatre of the oppressed. Publicación electrónica: http://www.unomaha.edu/ paterson/. Julio, 1999.

PÉREZ DE CUÉLLAR y otros (1997) Nuestra diversidad creativa. Unesco/Fundación Santa María. Madrid.

SALVAT, R. (1988) El teatro. Montesinos. Barcelona.

TEATRO CAMALEÓN. Prenez-garde au caméléon! Publicación electrónica: http://pages.infinit.net/cameleon/presentation.html. Julio, 1999.

UBERSFELD, A. (1989) Semiótica teatral. Ed. Cátedra/Universidad de Murcia. Madrid.

- (1997) La escuela del espectador. Asociación de directores de escena de España. Madrid.

ÚCAR, X. (1992a) El teatro en la animación sociocultural. Técnicas de intervención. Diagrama. Zaragoza.

- (1992b) La animación sociocultural. Ceac. Barcelona.

- (1993) “La animación teatral: los procesos de evaluación de intervenciones socioculturales implementadas por medio de técnicas y elementos teatrales.n, pp. 159-177. Teoría de la educación. Revista Interuniversitaria de Teoría de la Educación. Vol. V. Universidad de Salamanca.

- (1997) "Animación sociocultural, complejidad y modelos de intervención" pp. 86-108, en Educación social. Revista de intervención socioeducativa. № 5. Enero-abril. Institut de Formació de la Fundació Pere Tarrés. Barcelona. 
TEORÍA Y PRÁCTICA DE LA ANIMACIÓN TEATRAL COMO MODALIDAD DE EDUCACIÓN NO FORMAL

- (1998a) «La complejidad de las acciones socioeducativas: animación sociocultural y procesos de sistematización", pp. 72/25-72/34, en GAIRÍN/FERRÁNDEZ Planificación y gestión de instituciones de formación. Praxis. Barcelona.

- (1998b) La animación como producción o acceso cultural. La animación teatral. Ponencia leída en el Seminario Internacional: Las perspectivas de animación sociocultural en América Latina: entre la gestión cultural y la mediación social. Universidad Externado de Colombia. Santa Fe de Bogotá (En prensa).

- (1999) "Nuestra diversidad creativa: una invitació a la lectura del informe Pérez de Cuéllar" pp. 84-92. Perspectiva escolar. № 237. Setiembre.

VENTOSA, V.J. (1996) La expresión dramática como medio de animación en educación social. Amaru. Salamanca.

- y JERIGONZA. (1990) Animación teatral. Ed. Popular. Madrid.

VIO, K. (1996) Explorando el match de improvisación. Naque. Ciudad Real.

WORLD COMMUNITIES. Center for community-based theatre. Documento electrónico: http://canes.gsw.peachnet.edu/ world/. Julio, 1999.

ZALLO, R. (1992) El mercado de la cultura. Hirugarren Prentsa. Donostia. 


\section{ANEXO 1. RECURSOS DE ANIMACIÓN TEATRAL EN LA RED}

1. Grupo de animación de fiestas infantiles (Cataluña. España). http://www.valser.es/llunatics/

2. ALQUINDOY. Empresa de Animación (Málaga. España).: http://www.aliquindoy.com/

3. TEATRO NUCLEO. Teatro para formación de operadores sociales (Ferrara. Italia): http://www.4net.com/nucleo/

4. GLOBAL IDEA. S.L. Empresa de servicios culturales. Animación teatral (Barcelona. España): http://retelcom.es/global/

5. Grupo de teatro. Ofrece animación teatral (La Rioja. España).: http://www.arrakis.es/ parv/ttt/

6. MUVA PRODUCCIONS. Empresa de servicios. Teatro, animación, escuela. (Alicante. España).: http://www.spainter.com/muva/

7. Escuela de teatro. Dinamización teatral (Cataluña. España).: http://www.geocities.com/Broadway/Alley/1514/\#

8. SALONETY. Empresa de cultura, ocio y desarrollos creativos. Ofrece Animaciones itinerantes y teatro de calle (Valencia. España).: http://ciberia.es/salonety/

9. LA TROCA. Grupo de animación infantil y juvenil. Fiestas y teatro. (Cataluña. España).: http://www.fut.es/ maige/

10. BAMTAARE. Grupo de teatro. Le théâtre au service de l'éducation au développement. Teatroforum. (Kaolack. Senegal) http://www.oneworld.org/euforic/eurodc/theatre.htm

11. A.C. PAPIEL TEATRO. Grupo de teatro/ Animación. (Zaragoza. España): http://www.aragon.net/aragon/web/grupos/papiel.htm

12. ASP. Empresa de animación sociocomunitaria. Ofrece fiestas y espectáculos (Ciudad Real. España): http://www.accindes.org/asp/menu2.html

13. O HIEROFANTE. Grupo de educación comunitaria a través del teatro (Brasilia. Brasil): http://www.abordo.com.br/hierofante/triimm.html

14. Groupe ATEL. Gestión y formación del ocio (Quebec. Canada): http://www.atel.qc.ca/mainpage.htm

15. Teatro universitario: improvisación y animación (Laussana. Suiza): http://agepwww.epfl.ch/PIP/

16. TEATRO CAMALEÓN: campañas de sensibilización, publicidad, animación, etc. (Montreal. Canada): http://pages.infinit.net/cameleon/presentation.html

17. Asociación no lucrativa que promueve el teatro entre los jóvenes (Francia): http://kmu.unil.ch/imoura/3/4/present.htm

18. LA DURÉE\&L'INTANT. Teatro al servicio de la prevención (toxicomanias, alcoholismo,violencia, suicidio de adolescentes y maltratos (París. Francia): http://www.ldeli.laligue.org/index.htm

19. ANNIE BERTRAND: Animación teatral en medio rural (Clermont-Ferran. Francia): http://www.citeweb.net/dejavu/abertrand/som2.htm

20. Animación teatral en un museo. Capsules d'animation théatrâle (Quebec. Canadá): http://www.mcq.org/webnew/dix_ans/educ_a.html

21. CENTRE DE RECHERCHE EN CIVILISATION CANADIENNE-FRANÇAISE: Fonds Théâtre Action (Ottawa. Canadá): http://aix1.uottawa.ca/academic/crccf/organismes/c64.html

22. GRUPE NATYA CHETANA. Teatro de concientización (India): http://www.men.lu/script/form/code2098.html

23. UNIVERSITE DE SHERBROOKE. Formación universitaria: El teatro de animación (Quebec. Canadá): http://www.usherb.ca/flsh/dlc/doss-ped/lit/lit470.html

24. ANIMAGINATION. Empresa de animación: teatro, marionetas y animaciones creativas animación (Quebec. Canadá): http://www.mediom.qc.ca/ boulange/anima.html

25. MISE AU JEU. Intervención teatral participativa: (Montreal. Canadá): http://www.cam.org/ maj/index.html

26. VIVA. Proyecto de formación teatral: Taller teatral y circense para niños de 8 a 12 años (Albergaria-a-Velha. Portugal): http://www.terravista.pt/Enseada/1283/projecto.html 
TEORÍA Y PRÁCTICA DE LA ANIMACIÓN TEATRAL COMO MODALIDAD DE EDUCACIÓN NO FORMAL

27. VIVA A ESCOLA. Prevención primaria en medio escolar. Usa la animación teatral entre otros recursos (Portugal): http://www.esec-loule.rcts.pt/40anos/pag10.htm

28. Programa de animación de fiestas. Incluye teatro popular (Aveiro. Portugal): http://www.ua.pt/cma/agenda/programa1.html

29. LA CARRETA. Grupo de teatro popular. Actividades de animación teatral (Chile): http://members.xoom.com/la_carreta/esp/carreta.html

30. UNIVERSITAT JAUME I. Formación teatral aplicada a la enseñanza (Castellón. España): http://sic.uji.es/com/notes/9807/98070673n.html

31. GROUPE SIGNE. Grupo de teatro. Formación y expresión teatral con bandicapés" (Lyon. Francia): http://www.imedserv.com/Signes/index.html

32. LA PASSIÓ. Animación sociocultural por medio del teatro: Una "Pasión" representada por todo un pueblo (Cataluña. España): http://www.infodisc.es/lapassio/espect.htm

33. PAPALLONA TEATRE. Grupo de teatro. Ofrece Teatro infantil, animacion teatral, teatro de calle, talleres de teatro, pasacalles (Valencia. España): http://www.metabusca.com/busca/meta/redirect.htm? http://www.arrakis.es/ elboig/@/busca/meta/resul/8/f8214.htm

34. GRUPO TEATRAL SABADO. Asociación civil cultural especializada en teatro: formación, comunicación, representación (Venezuela).: http://www.bcity.com/gruposabado/index.html?inFrame

35. CIA. LAS CALIGULAS. Grupo de teatro. Ofrece animaciones y acciones teatrales: http://bbs.seker.es/ las_caligulas/carta_en.html

36. NITE LITE THEATRE OF GIBSON COUNTY, INC. Organización rural que usa el teatro como elemento educativo (Tenesse.EEUU): http://www.nitelite.tn.org/

37. NTTC. Corporación educativa sin animo de lucho que realiza actividades teatrales en comunidades (Boston.EE:UU): http://www.world.std.com/ netc/index.html

38. COMMUNITY IN MOTION. Texto: Teatro para el desarrollo en Africa (New York. EE.UU.): http://info.greenwood.com/books/0897895/0897895819.html

39. WORLD COMMUNITIES. Center for community-based theatre-Georgia Southwestern State University. Ofrecen a las comunidades trabajar con ellas para recoger y explicar su historia y cultura mediante el teatro (Georgia. EE.UU.): http://canes.gsw.peachnet.edu/ world/

40. PEDAGOGY \& THEATRE OF THE OPPRESSED. Forum global para promover el pensamiento crítico y la justicia social a través del teatro Omaha University (Omaha. EE.UU.): http://www.unomaha.edu/ p pto/ptolinks.htm

41. STAGING AREAS. Boletin informativo sobre comunidades que trabajan el cambio social a través del teatro (EE.UU.): http://csep.sunyit.edu/ joel/STAGING/MISSIONS.HTM

42. ANIMATION: what's in a name. Documento: Habla sobre animación en general pero se refiere a menudo a la animación teatral a través de ejemplos concretos. (California. EE.UU.): http://www.wwcd.org/action/animation.html

43. ALTERNATE ROOTS. Organización regional que trabaja a través de las artes (teatro) en comunidades. (Atlanta. EE.UU): http://home.earthlink.net/ altroots1/

44. ART IN THE PUBLIC INTEREST. Enlaces a páginas web que relacionan artes, educación y desarrollo social. Hay algunas centradas en el teatro en concreto (EE.UU).http://www.artswire.org/Community/highperf/api/APIothersites.html

45. APLIED AND INTERACTIVE THEATRE GUIDE. Recursos sobre técnicas teatrales (drama terapia; psicodrama; sociodrama; teatro del oprimido; teatro interactivo; improvisación; objetivos comunitarios, etc) y forum de discusión (EE.UU): http://pages.nyu.edu/ as245/AITG/

46. THE UpROOTED! EXPERIENCE. Caso-estudio: proyecto teatral en una comunidad rural maderera. (Omaha. EE.UU.): http://www.wwcd.org/action/uprooted.html

47. TRAINING AND DEVELOPMENT. Relación de grupos especializados en recursos humanos y de formación para el desarrollo comunitario y organizacional (EE.UU): http://pages.nyu.edu/ as245/AITG/training.html 
48. HEADLINES THEATRE. THEATRE FOR LIVING. Grupo de teatro. Usan técnicas del "teatro del oprimido" para trabajar con comunidades (Vancouver. Canadá):

http://www.headlinestheatre.com/intro.htm

49. THE IMPROBABLE PLAYERS. Teatro para la educación y la prevención.(Boston. EE.UU. http://www.xensei.com/users/players/

50. SOCIAL ACTION THEATRE. Organización de la Universidad de Wisconsin. Trabajan Teatroacción. (Wisconsin. EE.UU.): http://www.uwm.edu/Dept/DSAD/TRAINING/sat.html

51. THÉÂTRE ACTION. Empresa de servicios que trabaja con compañias profesionales, los grupos comunitarios y escolares y los artistas (Ontario. Canadá). http://www.theatreaction.on.ca/

52. QUAND LE THÉÂTRE FAIT BOUGER LA SOCIÉTÉ: Texto. Se refiere a TRACT (troupe de recherche, d'animation et de communication théâtrale) organización que agrupa a seis grupos de teatro que viven y trabajan en Mali (Mali): http://www.monde-diplomatique.fr/1998/09/HEYMANN/10928.html

53. LE MODERNE. Asociación sin ánimo de lucro y grupo de teatro. (Liege. Belgica): http://www.moderne.org/Presentation.html

54. ACPC's THEATRE (The Asian Council for People's Culture). Theatre for the Environement Network. Organización nacional (Quezon. Filipinas): http://fortunecity.com/victorian7museum/422/acpc2.html

55. CATS (Community Asian Theater of the Sierra). Organización sin ánimo de lucro. (Nevada. EE.UU): htpp://www.ncgold.com/TheArts/Theatre/CATS

56. The American Association of Community Theatre (AACT) Organización sin ánimo de lucro: Ofrece un amplio rango de oportunidades para compartir experiencias, problemas, eventos y amar el teatro (EE.UU): http://www.aact.org.html

57. FOUNDATION VIRTUELLE POUR LE DÉVELOPPEMENT DU THÉÂTRE SOCIAL. Contribución a un forum (Francia). http://www.ideact.com/forum/thea/messages/102.html

58. THÉÂTRE DANS LES HOSPITAUX. Contribución a un forum (Santa Catarina. Brasil): http://Ideact.com/forum/thea/messages.148.html

59. THEATRE FOR DEVELOPMENT. Texto (Africa): http://www.mediaport.net/AeC/Theatre/theatre_utile.en.html

60. BOTSWANA. Drama in Botswana. Grupo no profesional de teatro: (Botswana.Africa): http://www.mediaport.net/AeC/Theatre/Pays/Botswana.en.html

61. BURKINA FASO. Texto: presenta la historia del Teatro para el desarrollo en este pais. (Burkina Faso, Africa): http://mediaport.net/AeC/Theatre/Pays7Burkina_Faso.en.html

62. MALI.. Texto: presenta la historia del Teatro para el desarrollo en este pais (Mali, Africa): http://www.mediaport.net/AeC/Theatre/Pays/Mali.en.html

63. ANADE es una Organización no Gubernamental, de carácter no lucrativo, de ámbito estatal Su objetivo es la rehabilitación e integración socio-laboral de personas con discapacidad, utilizando para ello el teatro y el cine (Castilla-La Mancha. España). http://www.anade.org/a00.htm 